\title{
Agreement with the internal possessor in Chimane:
}

\section{A mediated locality approach}

\author{
Sandy F. Ritchie
}

\begin{abstract}
The paper examines a type of clausal construction in Chimane (or Tsimane', unclassified, Bolivia) in which possessors which are apparently internal to patient- or recipient-like possessive phrases can control object agreement on the verb. Various aspects of the construction point to an analysis in which the internal possessor is doubled by an external representation or 'proxy' in the clause which mediates the agreement relation between the possessor and the verb. The construction bears some resemblance to external possessor constructions, albeit with the added complication that the possessor itself remains internal to the possessive phrase while its argument function is borne by the external proxy. The paper examines features of the construction and contrasts it with similar or related phenomena which have been identified in other languages.
\end{abstract}

\section{Introduction}

Possessors in attributive possessive constructions have an unusual status in grammar, since they can refer to semantically and information structurally prominent entities, but have a 'lowly' syntactic status, functioning as specifiers or modifiers internal to the phrase headed by the possessed noun. Many languages have a strategy for iconically signalling 
This is the accepted version of an article published by John Benjamins in Studies in Language Vol. 41 (3), 660-716. Published online 25 October 2017. Available from: https://doi.org/10.1075/sl.41.3.05rit Accepted version downloaded from SOAS Research Online: https://eprints.soas.ac.uk/25082/

21 semantically or information structurally prominent possessors, which typically involves 
This is the accepted version of an article published by John Benjamins in Studies in Language Vol. 41 (3), 660-716. Published online 25 October 2017. Available from: https://doi.org/10.1075/sl.41.3.05rit Accepted version downloaded from SOAS Research Online: https://eprints.soas.ac.uk/25082/

'raising ${ }^{1}$ of the internal possessor out of the phrase and into a clause-level position (Payne \& Barshi 1999). Typically, these 'external possessors' (EPs) assume the status of a core argument like subject or object, while the phrase containing the possessed noun is demoted to the status of an oblique or secondary object argument. This is the case in English external possessor constructions (EPCs) like I touched John on the arm, ${ }^{2}$ where the possessor John assumes the status of the object and the possessed noun arm is demoted to the status of an oblique adjunct. Compare this EPC with its non-EPC counterpart $I$ touched $J o h n$ 's arm, where the possessor is internal to the phrase head by the possessed noun, and this entire possessive phrase functions as the object of the verb. Since possessors assume an argument status in EPCs, they can participate in clause-level syntactic processes such as predicate-argument agreement.

However, EPCs are not the only strategy by which possessor prominence can be signalled. There is also a family of constructions attested in several genetically unrelated languages in which possessors which are apparently internal to the phrase containing the possessed noun can control agreement on the verbal predicate. These may include Tangut (Kepping 1979), Tabassaran (Kibrik \& Seleznev 1980; Mel'čuk 2001), Choctaw (Davies 1984), Maithili (Stump \& Yadav 1988; Bickel et al. 1999), Magahi (Verma 1991), Burushaski (Willson 1996), Jarawara (Dixon 2000), Santali (Neukom 2000), Itelmen (Bobaljik \& Wurmbrand 2002), Salish languages (Kiyosawa 2004), Rajbanshi (Wilde 2008), Aleut (Golovko 2009), Chol (Vázquez Álvarez 2011), Tseltal (Shklovsky 2012), Bajjika (Kashyap 2012), Darai (Dhakal 2015), Mi'gmaq (Hamilton to appear) and Ngumpin-Yapa languages (Meakins \& Nordlinger under review).

These 'prominent internal possessor constructions' (PIPCs) (Nikolaeva 2014b) defy simple explanation, because an element in one syntactic domain (the phrase containing the possessed noun) is somehow able to participate in syntactic processes in another domain (the clause). This kind of configuration is (at least on initial inspection) in violation

\footnotetext{
${ }^{1}$ This term is used descriptively here, without assuming movement of the possessor.

${ }^{2}$ The English construction is usually analysed as a possessor raising construction. I used the term 'external possessor construction' here and throughout the paper to refer more generally to any construction in any language in which the possessor is external to the phrase headed by the possessed nominal.
} 
This is the accepted version of an article published by John Benjamins in Studies in Language Vol. 41

(3), 660-716. Published online 25 October 2017. Available from: https://doi.org/10.1075/sl.41.3.05rit Accepted version downloaded from SOAS Research Online: https://eprints.soas.ac.uk/25082/

\footnotetext{
${ }^{3} \mathrm{~A}$ local domain is a syntactic environment in which elements interact with each other morphosyntactically. Some typical examples are the noun phrase, in which a head and its dependents interact with each other and the clause, in which the verb and its arguments interact with each other.

${ }^{4}$ In this example and throughout this study, brackets are used to indicate constituency, though as a reviewer notes, evidence for constituency in Chimane is not clear, so the brackets should be taken primarily as aids to understanding rather than an analysis. Indices are used to show agreement between targets and controllers and coindexing of antecedents and anaphors. As far as possible, possessed nouns and possessive phrases headed by possessed nouns are indicated by a subscript $i$, while possessors are indicated by a subscript $j$, for example $\left[\text { Mary }{ }_{j}{ }^{\prime} \text { s children }\right]_{i}$.
} 
This is the accepted version of an article published by John Benjamins in Studies in Language Vol. 41

(3), 660-716. Published online 25 October 2017. Available from: https://doi.org/10.1075/sl.41.3.05rit Accepted version downloaded from SOAS Research Online: https://eprints.soas.ac.uk/25082/

71 with an EPC, in which the possessor occurs in a position external to the phrase containing 72 the possessed noun and functions as the object of the verb. The EPC is shown in (1b). 73 Unusually, however, the event can also be expressed in Chimane by a third construction

\footnotetext{
${ }^{5} \mathrm{~A}$ list of glossing abbreviations used in this paper can be found immediately following Section 8 . The verbs in the examples in (1) also feature verbal classifiers which are glossed as CLF. These are suffixes which obligatorily occur with most verbal roots to create inflectable stems. They have various meanings related to subject control and transitivity - see also Sakel (2004; 2007).
} 
This is the accepted version of an article published by John Benjamins in Studies in Language Vol. 41 (3), 660-716. Published online 25 October 2017. Available from: https://doi.org/10.1075/sl.41.3.05rit Accepted version downloaded from SOAS Research Online: https://eprints.soas.ac.uk/25082/ 119 construction, termed by Comrie (2003) as ‘trigger-happy’ agreement, in which agreement 120 does not correlate one-to-one with grammatical functions but can instead be controlled by

object of the verb in this construction. The possessed noun occurs in combination with the superessive -che', indicating that it functions as an oblique adjunct.

In the PIPC in (1c), just as in the IPC, the possessor exhibits nominal agreement with the possessed noun (indicated by the $-s$ suffix). This shows that it is a dependent of the possessed noun. However, just as in the EPC, it also appears to control object agreement on the verb instead of the possessed noun. The possessive phrase headed by the possessed noun cannot be the controller of agreement here, as there would be a mismatch in gender; the possessed noun is feminine and the as the agreement suffix -te indicates a third person singular masculine object. The only other possible controller of this agreement suffix appears to be the masculine internal possessor. The verb also exhibits the applicative suffix - $b i$ in the PIPC (the nature of this suffix is discussed in more detail later).

As these examples show, the PIPC in (1c) shares features with both the IPC in (1a) and the EPC in (1b). It shares with the IPC the fact that the possessor exhibits nominal agreement with the possessed noun. Meanwhile, it shares with the EPC the fact that the possessor controls object agreement on the verb. The PIPC therefore presents a problem, as the status of the possessor in this construction is not clear. The nominal agreement marking on the possessor suggests that it is internal to the possessive phrase, while the fact that it can control object agreement on the verb suggests that it functions as the object of the verb, and therefore has a realization in the clause external to the possessive phrase.

The aim of this paper is to consider this dual status of prominent internal possessors (PIPs) in Chimane, and to show that they require a different kind of analysis from external possessors like that in (1b). An additional aim is to compare Chimane PIPs with similar phenomena in other languages. This comparison shows that the Chimane PIPC represents a kind of intermediate stage between fully-fledged EPCs and a different type of a range of non-arguments including internal possessors.

The paper is structured as follows. In Section 2, some background information on 
This is the accepted version of an article published by John Benjamins in Studies in Language Vol. 41 (3), 660-716. Published online 25 October 2017. Available from: https://doi.org/10.1075/sl.41.3.05rit Accepted version downloaded from SOAS Research Online: https://eprints.soas.ac.uk/25082/

Chimane is given. In Section 3, some information about the data presented in the study is summarised. Section 4 offers some background on Chimane grammar and includes a basic description of the structure of possessive noun phrases and the syntax of simple declarative clauses. The structure of PIPCs and the morphosyntactic status of PIPs are considered in Section 5, and in Section 6 an evaluation of various potential analyses of PIPCs which have been proposed for similar or related constructions in other languages is provided. In Section 7, the proposed analysis of Chimane PIPCs is set out. Finally in Section 8 , a summary is given and directions for further research are identified.

\section{Language background}

This section summarizes some basic facts about the language, including its genetic affiliation, the area where it is spoken, the number of speakers, its sociolinguistic status and an overview of some previous work on the language. For further information about the Chimane people and their language, see Daillant (2003), Sakel (2004) and Huanca (2005), amongst others.

\subsection{Language name}

The Chimanes' self-designation is Tsimane'. When they wish to distinguish themselves from outsiders, they sometimes also refer to themselves as muntyi' (in) 'person, people'. They refer to their language as tsunsi' peyacdye' 'our language', or more commonly just as tsunsi'ĉan, literally 'in ours'. In the past the Chimanes have variously been referred to by outsiders as Chimanisa, Chumano, Chimani and Nawazi-moñtji (Métraux 1942). Nowadays the most commonly used designation is Tsimane'. In this study I use the more traditional spelling variant, following the convention of previous work on the language written in English. 
This is the accepted version of an article published by John Benjamins in Studies in Language Vol. 41 (3), 660-716. Published online 25 October 2017. Available from: https://doi.org/10.1075/sl.41.3.05rit Accepted version downloaded from SOAS Research Online: https://eprints.soas.ac.uk/25082/

\subsection{Genetic affiliation}

Chimane is closely related to Mosetén, which has two varieties corresponding to the two villages where it is spoken: Santa Ana and Covendo. According to Sakel (2004), Santa Ana Mosetén shares similarities with both Chimane and Covendo Mosetén, whereas the latter two exhibit more differences. She therefore proposes that the three varieties form a dialect continuum with Chimane at one end, Santa Ana Mosetén in the middle and

Covendo Mosetén at the other end. She characterises the continuum as a small language family, calling it Mosetenan. I will not follow this terminology as it seems more likely that what we are dealing with is a single language with three divergent but still partially mutually comprehensible dialects. I will therefore use the term Chimane-Mosetén to refer to the dialect continuum.

There have been proposals linking Chimane-Mosetén to other language families. Swadesh (1963) claims that it shares $34 \%$ of its vocabulary with Ona and almost as much with Tehuelche, which form part of the Chon family. Suárez (1969) attempts to link it to the Panoan and Tacanan languages, using phonological and lexical correspondences as evidence. Suárez (1973) proposes a Macro-Pano-Tacanan stock, linking Chimane-Mosetén and Chon with Panoan and Tacanan languages as well as other languages including Yurakaré. Greenberg (1987) proposes an even broader grouping, linking Chimane-Mosetén with Panoan, Tacanan, Jê and Carib languages. All these comparisons are based on the vocabulary lists found in Bibolotti (1917), which Suárez acknowledges as being an unreliable source due to inconsistencies in the transcription. Kaufman (1990) broadly agrees with these groupings, but they are disputed by Sakel (2004), Van Gijn (2006) and Guillaume (2008) (amongst others), who point out that Swadesh, Suárez and Greenberg rely too heavily on the comparison of first and second person pronominals, which may in fact be an areal feature as they are also shared by other South American languages. Many of the other lexical similarities they cite are contentious or may be explained as examples of borrowing (Campbell 1997; Adelaar \& Muysken 2004). A more detailed reconstruction is required to prove the genetic relationship of Chimane-Mosetén to any other language. 
This is the accepted version of an article published by John Benjamins in Studies in Language Vol. 41 (3), 660-716. Published online 25 October 2017. Available from: https://doi.org/10.1075/sl.41.3.05rit Accepted version downloaded from SOAS Research Online: https://eprints.soas.ac.uk/25082/

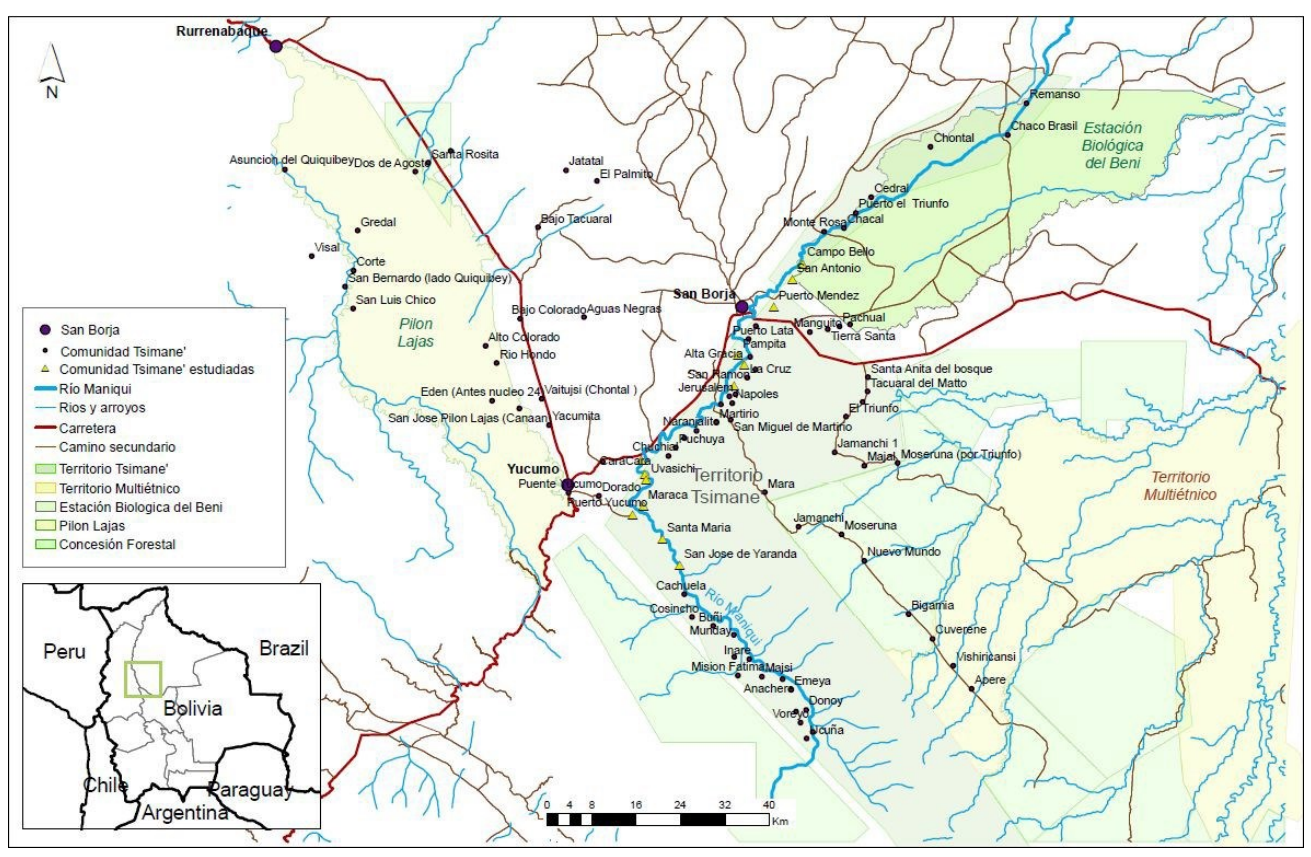

Figure 1: Map of Chimane speaking communities

\subsection{Geography and demography}

${ }_{187}$ Estimates of the number of ethnic Chimanes vary. The latest census (2012) reports 16,958 Their traditional territory was in the forested foothills of the Marimonos and Eva Eva mountains, but in recent years they have also settled in the savannah extending from the town of San Borja down the Maniqui river (see Figure 1). Administratively, their territories fall within the Beni department of Bolivia, though the Chimanes have legal rights to most of the territories where they live.

Most Chimanes still live in traditional communities, though some live in mixed communities with the Andean settlers who also inhabit the area. A small number also live in San Borja, especially those involved in politics and commerce. There are also a few outlying communities outside the Beni region, notably Ixiamas in La Paz department and several communities around the town of Yucumo (Huanca 2005).

\subsection{The number of speakers}

people. This represents a large increase from the previous census (2001) which reported

The Chimanes live in the Amazonian rainforests of northern Bolivia (South America). 
This is the accepted version of an article published by John Benjamins in Studies in Language Vol. 41 (3), 660-716. Published online 25 October 2017. Available from: https://doi.org/10.1075/sl.41.3.05rit Accepted version downloaded from SOAS Research Online: https://eprints.soas.ac.uk/25082/

just 4,331 people. However, it is likely that there were methodological problems in the collection of data for the 2001 census, so while the increase was probably not as dramatic as these figures suggest, the population does appear to have grown significantly in recent years. Unfortunately the census reports do not include information about the number of speakers of the language. In an earlier study, Crevels estimates "...approximately 6,350 speakers, amongst 8,615 people" (2009: 297$){ }^{6}$ According to this estimate, $74 \%$ of the people speak the language. Given that nearly all Chimanes are monolingual and do not begin to learn Spanish systematically until their teenage years (if at all, see Section 2.5), the actual figure may be even higher, perhaps as high as 85-90\%. Applying these estimates to the results of the last census, the number of speakers of the language may be estimated to be somewhere in the region of 12,500 to 15,000 . This is a unique situation amongst the indigenous languages of Amazonian Bolivia; no other language has such a high proportion of speakers and such a relatively large population. Most other indigenous languages in the region are either highly endangered or already on the verge of extinction.

\subsection{Sociolinguistic situation}

Chimane is still the primary means of communication in all spheres of life for the majority of the people. Crevels states that "the vitality of the language is very high, especially amongst women and older people, who speak very little Spanish. In some communities, the children do not learn Spanish until they are fifteen years old, unless they attend school in one of the Andean colonists' communities" (2009: 297). These observations fit well with my experience in the communities. While younger and middle-aged men typically have at least some rudimentary knowledge of Spanish (usually attained through their employment as labourers and farmhands), women, children and older people are typically monolingual speakers of Chimane. Crevels states that Chimane is only "potentially endangered' (or 'vulnerable' in the UNESCO terminology). All the other Amazonian Bolivian languages she cites in the chapter are endangered or worse. Mosetén, for example,

${ }^{6}$ All translations of quotations from non-English sources are my own. 
This is the accepted version of an article published by John Benjamins in Studies in Language Vol. 41 (3), 660-716. Published online 25 October 2017. Available from: https://doi.org/10.1075/sl.41.3.05rit Accepted version downloaded from SOAS Research Online: https://eprints.soas.ac.uk/25082/

has no monolingual speakers and is slowly disappearing (Sakel 2004).

\subsection{Environment, subsistence and culture}

Chimane communities are typically located along streams and rivers, with a great many strung out along the Maniqui river. The Maniqui has a central place in Chimane life, reflected in its name Cojiro, which is also the generic term for a river. Some communities are located deep in the jungle, with others on the savannah. Rivers are the primary means of transport, with paths and roads of only secondary importance. The altitude varies from around 200 to 1,000 metres above sea level. The climate is tropical with a mean temperature of around $26^{\circ} \mathrm{C}$. There are two main seasons: the rainy season from December to March and the dry season from June to September. The temperature can drop to as low as $10^{\circ} \mathrm{C}$ during the dry season when cold winds from the south blow up over the Maniqui.

The Chimanes' primary means of subsistence are hunting, fishing, gathering wild fruit and vegetables, and slashing and burning areas of the forest to cultivate crops such as plantain, rice and manioc. They also raise livestock including chicken, pigs, and cattle. Some Chimanes take part in the cash economy by selling surplus produce. Many men are also employed as labourers and farmhands by loggers and ranchers.

The Chimanes are gentle and non-confrontational in nature and place great value on their relationships. When they are not working, much of their time is spent visiting friends and relatives at their houses. Once appointed on palm mats, guests are offered shocdye' or chicha, an alcoholic drink made by boiling and chewing manioc and then leaving it to ferment for a day or two. The chicha is served in a large gourd bowl which is passed around and constantly refilled until everyone is satisfied. While traditionally wary of outsiders, the Chimanes are welcoming and accommodating of non-Chimanes who speak their language. Such people are referred to as chätidye' 'kin, relative' rather than by their name.

The Chimanes have a complex belief system based around a pantheon of gods who created the world and who shepherd and protect the various plants and animals of the 
This is the accepted version of an article published by John Benjamins in Studies in Language Vol. 41 (3), 660-716. Published online 25 October 2017. Available from: https://doi.org/10.1075/sl.41.3.05rit Accepted version downloaded from SOAS Research Online: https://eprints.soas.ac.uk/25082/

forests and rivers. These gods and the stories relating to them are discussed in detail by Huanca (2005). Central to the Chimane mythos are Dojity and Micha', two brothers who created the world and transformed primordial anthropomorphic beings into the animals of the forest. They also taught humans how to hunt and fish in an appropriate way. Another myth explains the creation of the Milky Way which traverses the Maniqui during the dry season. An old woman cared for a lizard called Noco who taught people how to fish during the dry season to reciprocate. The lizard then transformed himself into a large animal and became the Milky Way which holds up the sky over the Earth.

\subsection{History}

We know little about the history of the Chimanes prior to their first contacts with Western explorers and colonisers. Archaeological evidence suggests that they or their predecessors have been living and hunting in their traditional territories since prehistoric times. Their oral history suggests that their larger communities such as La Cruz and Nápoles developed from hunting grounds and meeting places which offered safe refuge (Huanca 2005). The first mention of the Chimanes in the Western tradition is in 1621 by the Franciscan missionary Gregorio de Bolívar, who describes them as "very good people, reasonable, well-dressed and friendly" (de Bolivar 1906, in Métraux 1942: 16). They are mentioned in several further reports of the 17th century as a numerous tribe living in 30 to 100 villages.

In the 18th and 19th centuries, successive missionary groups established more permanent missions in Chimane territories, notably the town of San Borja which was established and destroyed on two separate occasions before becoming more permanently established with the creation of the Beni department in 1842. Despite the missionaries' attempts to convert the Chimanes to Christianity, they have largely retained their own belief system. The reasons why the missionaries failed to convert them may include their relatively large population size, the difficulty involved in navigating their territory, their collective memory of epidemics brought by white people, injustices done against them by early 
This is the accepted version of an article published by John Benjamins in Studies in Language Vol. 41 (3), 660-716. Published online 25 October 2017. Available from: https://doi.org/10.1075/sl.41.3.05rit Accepted version downloaded from SOAS Research Online: https://eprints.soas.ac.uk/25082/

missionaries, and various aspects of their social organization. They traditionally lived in small mobile groups, allowing them to escape the missionaries. Shamans also held a strong influence over the people, which precluded the imposition of other religious ideas (Huanca 2005).

In the 20th century the Chimanes had much more extensive contact with outsiders due to the development of San Borja as a centre of trade, and in 1976 with the opening of roads from the highlands to the Beni department. These transport routes encouraged many more people to settle in the region, who began to exploit the rainforest in a much more extensive and systematic way, clearing large swathes of it to sell timber, raise cattle and establish new towns and villages. These changes have dramatically affected the Chimanes' way of life, as many of their traditional hunting grounds have been depleted or destroyed by the environmental changes. In the 1990s they participated in the Indigenous Land Demand which compelled the Bolivian government to grant them legal rights over their territories. Despite these changes, the incursions of outsiders continue and the Chimanes are adapting to this new reality by assimilating aspects of mainstream Bolivian culture and lifestyle in areas of close contact while retaining their traditional way of life in more remote communities.

\subsection{Previous studies}

A comprehensive overview of work on Mosetén and Chimane carried out in the 19th and 20th centuries can be found in Sakel (2004: Section 1.4). A significant early work was by the Italian Franciscan priest Benigno Bibolotti, who went to the mission at Covendo in 1857 and collected extensive lexical and grammatical information on Mosetén. This work was later found in a collection of manuscripts at Northeastern University by Rudolph Schuller, who reworked Bibolotti's materials and published them as Bibolotti (1917). This work was the primary source of information on Chimane-Mosetén until the arrival of the American Protestant missionary Wayne Gill in the community in the early 1980s.

Gill lived with the Chimanes for over 20 years, during which time he devised the or- 
This is the accepted version of an article published by John Benjamins in Studies in Language Vol. 41 (3), 660-716. Published online 25 October 2017. Available from: https://doi.org/10.1075/sl.41.3.05rit Accepted version downloaded from SOAS Research Online: https://eprints.soas.ac.uk/25082/

thography still in use today and produced several works on the language, including a substantial bidirectional Chimane-English dictionary (Gill 1999a) and a shorter bidirectional Chimane-Spanish version (Gill 1993). The Chimane-English dictionary has over 5,000 entries, with the meaning of each entry explained, exemplified and cross-referenced to other entries where appropriate. He also wrote a "teach-yourself" guide to Chimane grammar (Gill 1999b) which organises many aspects of the grammar into lessons intended for English-speaking learners of the language. Other works by Gill are a complete translation of the Bible and several pedagogical works including children's story books with parallel Chimane-Spanish texts (e.g. Gill 1987).

In the 1990s the Argentinean researcher Eusebia H. Martín produced several short papers dealing with aspects of Chimane grammar (see Sakel 2004: 11 for the full list). The French linguist Colette Grinevald also produced an alternative orthography as part of her alphabeticization project for lowland Bolivian languages (Grinevald 1996). This system was adopted by the Mosetenes but not by the Chimanes, who continue to use Gill's orthography. The two systems with IPA equivalents are shown in Table 1.

\begin{tabular}{|c|c|c|c|c|c|c|c|c|c|c|c|}
\hline \multicolumn{3}{|c|}{ Vowels } & \multicolumn{3}{|c|}{ Plosives } & \multicolumn{3}{|c|}{ Fric./Affr. } & \multicolumn{3}{|c|}{ Nas./Tr./Appr. } \\
\hline IPA & Chi. & Mos. & IPA & Chi. & Mos. & IPA & Chi. & Mos. & IPA & Chi. & Mos. \\
\hline $\mathrm{i} \sim \tilde{1}$ & $\mathrm{i} \sim \mathrm{i}$. & $\mathrm{i} \sim \ddot{\mathrm{i}}$ & $\mathrm{p}$ & $\mathrm{p}$ & $\mathrm{p}$ & $\mathrm{f}$ & $\mathrm{f}$ & $\mathrm{f}$ & $\mathrm{m}$ & $\mathrm{m}$ & $\mathrm{m}$ \\
\hline$\dot{\mathrm{i}} \sim \tilde{\mathrm{I}}$ & $\mathrm{u} \sim \mathrm{u}$ & - & $\mathrm{p}^{\mathrm{h}}$ & $\hat{\mathrm{p}}$ & $\mathrm{ph}$ & $\mathrm{S}$ & $\mathrm{s}$ & $\mathrm{s}$ & $\mathrm{n}$ & $\mathrm{n}$ & $\mathrm{n}$ \\
\hline $\mathrm{e} \sim \mathrm{e}^{\sim}$ & $\mathrm{e} \sim \mathrm{e}$ & $\mathrm{e} \sim \ddot{\mathrm{e}}$ & t & $\mathrm{t}$ & $\mathrm{t}$ & $\mathrm{S}$ & sh & sh & $\mathrm{n}$ & $\mathrm{n}$ & $\mathrm{n}$ \\
\hline @ @ & $\ddot{a} \sim$ ä & $\mathrm{ae} \sim$ äe & 1 & $\mathrm{t}$ & $\mathrm{t}$ & $\mathrm{h}$ & $\mathrm{j}$ & $\mathrm{j}$ & $\tilde{\mathrm{n}}$ & $\tilde{\mathrm{n}}$ & $\tilde{\mathrm{n}}$ \\
\hline $\mathrm{a} \sim \tilde{\mathrm{a}}$ & $\mathrm{a} \sim \mathrm{a}$ & $\mathrm{a} \sim \ddot{\mathrm{a}}$ & $t^{j}$ & ty & ty & ts & ts & ts & $\mathrm{r}$ & $\mathrm{r}$ & $\mathrm{r}$ \\
\hline \multirow[t]{7}{*}{$\mathrm{O} \sim \tilde{\mathrm{O}}$} & $\mathrm{o} \sim \mathrm{o}$. & $\mathrm{O} \sim \ddot{\mathrm{o}}$ & $\mathrm{k}$ & $\mathrm{c}, \mathrm{qu}$ & $\mathrm{k}$ & $\mathrm{ts}^{\mathrm{h}}$ & ts & tsh & V & $\mathrm{v}$ & w \\
\hline & & & $\mathrm{k}^{\mathrm{h}}$ & $\hat{c}, \hat{q} u$ & $\mathrm{kh}$ & tS & $\mathrm{ch}$ & $\mathrm{ch}$ & $\mathrm{j}$ & $\mathrm{y}$ & $\mathrm{y}$ \\
\hline & & & $\mathrm{P}$ & & , & $t S^{h}$ & chh & chh & & & \\
\hline & & & $\mathrm{b}$ & $\mathrm{b}$ & $\mathrm{b}$ & & & & & & \\
\hline & & & "d & $\mathrm{d}$ & $\mathrm{d}$ & & & & & & \\
\hline & & & $d$ & $d$ & $d$ & & & & & & \\
\hline & & & $\mathrm{d}^{\mathrm{j}}$ & dy & dy & & & & & & \\
\hline
\end{tabular}

Table 1: Comparison of Chimane and Mosetén writing systems with IPA 
This is the accepted version of an article published by John Benjamins in Studies in Language Vol. 41 (3), 660-716. Published online 25 October 2017. Available from: https://doi.org/10.1075/sl.41.3.05rit Accepted version downloaded from SOAS Research Online: https://eprints.soas.ac.uk/25082/

In 1999, the German linguist Jeanette Sakel began a research project on Mosetén. She carried out fieldwork with the community in Covendo and has produced a series of works on the language, including a reference grammar (Sakel 2004) and papers on gender agreement (Sakel 2002), clusivity ${ }^{7}$ (Sakel 2005), verbal classes (Sakel 2007) and argument coding (Sakel 2011). She also produced a grammatical sketch of Mosetén and Chimane in Spanish (Sakel 2009). In 2012, a team of American cognitive scientists led by Ted Gibson began investigating Chimane children's development and mastery of number and colour concepts. They have published papers on the trajectory of Chimane children's acquisition of number words (Piantadosi et al. 2014; Jara-Ettinger et al. 2015; Jara-Ettinger et al. in press) and have a number of other papers in preparation.

\section{The data}

The data presented in this paper come from several sources. The primary source is materials collected and developed in the course of my own fieldwork, which I conducted in Chimane communities from September to December 2012, June to July 2013 and June to September 2014. Approximately six hours of this data was transcribed, translated and interlinearized with morpheme-level glosses, which along with around 2,000 elicited example sentences make up the main body of the corpus used for the analysis. Secondary sources include Gill's grammar (1999b), the Chimane-English dictionary (1999a) and various Chimane texts published by Gill and other authors. All the data presented in the thesis have been checked with several native speakers and the grammaticality judgements presented are theirs.

Throughout my time in the field I used Spanish to conduct elicitation sessions. Though I have tried to draw on naturalistic data as far as possible, in many cases the examples presented here come from the more artificial parts of the corpus, i.e. elicited translations

${ }^{7}$ Clusivity is the distinction between inclusive and exclusive first person pronouns, i.e. whether or not the addressee(s) are included in or excluded from the reference of first person pronouns (e.g. Filimonova 2005). 
This is the accepted version of an article published by John Benjamins in Studies in Language Vol. 41 (3), 660-716. Published online 25 October 2017. Available from: https://doi.org/10.1075/sl.41.3.05rit Accepted version downloaded from SOAS Research Online: https://eprints.soas.ac.uk/25082/

of Spanish sentences or (un)grammatical sentences of Chimane constructed by me. This is due to the nature of the investigation, which relies on speakers' judgements of the grammaticality of constructions which contain PIPs.

\subsection{Elicitation}

Elicitation data was gathered using the following methods. First I devised sentences in Spanish and asked the consultants to translate them into Chimane. I then manipulated the translated sentences, adding, removing or changing words or suffixes or changing their order. I then asked for grammaticality judgements of the new constructions. If the constructed examples were deemed to be grammatical, I asked for translations of them back into Spanish. I compared these with the original Spanish sentences and devise new sentences in Spanish in order to draw out further distinctions or to clarify the meaning of the Chimane sentences.

In order to check the validity of the consultants' grammaticality judgements, I crosschecked the sentences with other native speakers. In cases of differences of opinion, I would discuss the alternatives with my primary consultants and we would decide whether their original judgements were valid or alternatively whether the construction in question was marginally acceptable, or only acceptable in the speech of certain (usually older) speakers. I also compared the elicited and constructed examples with naturalistic examples from the documentary corpus. This latter method allowed me to see how the consultants' grammaticality judgements matched up with what is found in spontaneous speech. In cases of discrepancies between the consultants' judgements and examples from the corpus, I played the original recordings back to the consultants and asked them about their meaning. In some cases this would lead to refinement of the elicited data, and in other cases it would throw up new structures which usually had different meanings from the target structures. 
This is the accepted version of an article published by John Benjamins in Studies in Language Vol. 41 (3), 660-716. Published online 25 October 2017. Available from: https://doi.org/10.1075/sl.41.3.05rit Accepted version downloaded from SOAS Research Online: https://eprints.soas.ac.uk/25082/

\subsection{Picture description tasks}

PIPCs and IPCs alternate in discourse, but speakers' motivations for selecting between the two types of construction are not immediately apparent. Both semantic and information structural factors may be at work in influencing speakers' choice of construction. therefore it was necessary to gain some quantifiable data on the alternation between PIPCs and IPCs in discourse. To this end, I designed two picture description tasks which involved participants either describing or answering questions about pictures of people or animals acting on their own or other people or animals' possessions. These materials were developed following recommendations for the creation of linguistic stimuli in Majid (2012). The two tasks were designed to draw out some common splits in the use of PIPCs versus IPCs, in particular inalienability, animacy and topicality.

\subsection{Other stimulus materials}

In order to gain some stimulus-based data which is comparable to that collected for studies on other languages, I also made use of some well-known stimulus materials including the Pear Story film (Chafe 1980), the Frog Story (Mayer 1969), the Circle of Dirt picture description task (Eisenbeiss et al. 1999) and the Staged Events video clips (Van Staden et al. 2001). These tasks were carried out with a small number of participants.

\subsection{Corpus}

The corpus data consists of transcriptions and translations of audio and video recordings of native speakers telling folktales and myths; their personal histories and memories of the past; observations about Chimane society and traditions, and procedural texts such as recipes. It also includes some examples of free conversation and a transcription of the film which I made in collaboration with the community in Puerto Mendez about their way of life. This film includes many speech genres, including descriptions of important cultural items and practices by people 'in situ', and also voice-over descriptions of the 
This is the accepted version of an article published by John Benjamins in Studies in Language Vol. 41 (3), 660-716. Published online 25 October 2017. Available from: https://doi.org/10.1075/sl.41.3.05rit Accepted version downloaded from SOAS Research Online: https://eprints.soas.ac.uk/25082/ 410 it either through explicit questions or a more general request to recount the story depicted 411

events in the film which were recorded after the film was edited together. The recordings were transcribed either by me or by a consultant and then translated into Spanish by a consultant. Complicated constructions or sections were identified and we worked together on them to achieve better transcriptions and translations.

\subsection{Glossing and example naming conventions}

All the examples in Chimane are written in a slightly modified version of the orthography developed by Gill and glossed with lexical equivalents in English or functional glosses which are based on the Leipzig Glossing Rules (Bickel et al. 2004). $\quad$ For glossing of pronominals, I have chosen to use English pronominal equivalents rather than featurebased glosses, so for example the Chimane first singular pronoun yu is glossed as 'I', 'me', or 'my' rather than ' $1 \mathrm{sG}$ '. The use of the nominative, accusative and genitive English pronouns in the gloss is purely for the sake of clarity and to aid the reader's understanding of the grammatical functions of the Chimane pronominals in each context.

Like all nominals in Chimane, pronominals do not exhibit any variance in their form depending on the grammatical function which they bear (i.e. casemarking).

Elicited examples are marked as such. Corpus examples are accompanied by an alphanumeric code which indicates their origin. This code is based on the example naming system developed by McGill (2009). The code is composed of six letters followed by two sets of three numbers. The first letter indicates the example type according to the typology of language documentation materials developed by Himmelmann (1998), which ranks materials according to their naturalness and spontaneity. The three text types indicated are staged, stimulated and observed. Staged recordings are those in which native speakers offered or were asked to talk about a topic or recount a narrative etc. 'on camera'. They are indicated by an 's'. Stimulated recordings are those in which native speakers were shown some audiovisual stimulus such as a film or picture book and asked to respond to or discuss the stimulus in another way. They are indicted by a ' $\mathrm{t}$ '. Observed recordings 
This is the accepted version of an article published by John Benjamins in Studies in Language Vol. 41 (3), 660-716. Published online 25 October 2017. Available from: https://doi.org/10.1075/sl.41.3.05rit Accepted version downloaded from SOAS Research Online: https://eprints.soas.ac.uk/25082/

are those in which native speakers did not offer or were not asked to perform any kind of linguistic task or performance 'on camera'. Instead, in observed recordings they talk freely in a manner similar to how they might talk 'off camera'. Observed recordings are indicated by an ' $o$ '.

The second letter indicates the type of recording (and therefore also the modality). The three types are audio recordings (indicated by an ' $a$ '), video recordings (indicated by a ' $v$ ') and written texts (indicated by a 'w'). Audio and video recordings are always of spoken language. The last four letters are an abbreviation of the contributor's name, for example Margarita Lero Cuata is indicated by the abbreviation 'malc'. The first three numbers indicate the session number of that particular contributor. The second three numbers after the full stop (.) indicate the clause number from the session. (2) is an example code:

$\begin{array}{llll}\text { (2) S- } \quad \text { V- } \quad \text { malc- } & 003 & .009 \\ \text { staged video of Margarita Lero Cuata number } 3 & \text { clause } 9\end{array}$

All the staged, stimulated and observed examples cited in this thesis can therefore be traced back to their original recording and transcription, which will be available from the Endangered Languages Archive at the School of Oriental and African Studies in London. ${ }^{8}$ The elicitation materials may also be made available at a later date.

\section{Grammar background}

Chimane shares certain features with other Amazonian languages; the following is a partial comparison with the features listed in Dixon \& Aikhenvald (1999: 8-9).

The language is head marking and is predominantly agglutinative, with only a few cases of fusion. It features the close central unrounded vowel /1/ and exhibits contrastive nasality in the vowel system. Bound pronominal forms marking possessors have the same form as bound pronominals marking arguments in the clause. It is predominantly suffixing, with only a single prefix position on the verbal predicate. Subordinate clauses typi-

\footnotetext{
${ }^{8}$ The corpus will be available at: http://elar.soas.ac.uk/deposit/0348
} 
This is the accepted version of an article published by John Benjamins in Studies in Language Vol. 41 (3), 660-716. Published online 25 October 2017. Available from: https://doi.org/10.1075/sl.41.3.05rit Accepted version downloaded from SOAS Research Online: https://eprints.soas.ac.uk/25082/

454 The fact that possessors exhibit the same nominal agreement suffixes as adjectives (-si'/-s

cally involve nominalized verbs. In other respects, Chimane is distinctly un-Amazonian. It does not have a complex classifier or gender system, but instead features a simple binary split between masculine and feminine gender. It also has an extensive oblique casemarking system (core case-marking does not occur) and an elaborate predicate-argument agreement system in which one or more agreement suffixes cross-reference both arguments of a transitive verb. It does not feature any incorporation of nouns, adverbs or adpositions. It also has a large class of numerals following a decimal system.

\subsection{Possessive noun phrase}

Noun phrases consist of a head and optional dependents. In possessive noun phrases, the head of the phrase corresponds to the possessed noun. Determiners and modifiers, including possessors, agree with the gender of the head noun (see also Sakel (2002) for more information on the gender agreement paradigms). This is shown in (3), where the determiners, possessors, and adjectives exhibit nominal agreement with the feminine head ococo and the masculine head .itsiquij:

$$
\begin{aligned}
& \text { a. mọ' Juan-si' där-si' ococo } \\
& \text { the.F Juan(M)-F big-F frog(F) } \\
& \text { 'Juan's big frog' } \\
& \text { b. mu' Juan-tyi' där-tyi' itsiquij } \\
& \text { the.M Juan(M)-M big-M jaguar(M) } \\
& \text { 'Juan's big jaguar' }
\end{aligned}
$$

for feminine heads and -tyi'/-ty for masculine heads), along with the fact that they can cooccur with determiners in the phrase, suggests that they are modifiers rather than specifiers - i.e. Chimane is 'adjectival-genitive' as opposed to 'determiner-genitive' in the sense of Lyons (1986).

With respect to constraints on the linear order of constituents in the NP, the only real restriction appears to be that heads and modifiers cannot precede determiners: 
${ }_{467}$ This restriction seems to indicate that the NP is a constituent with some internal structure.

Apart from this 'determiner-first' restriction, the other constituents can occur in any order. The examples in (5) are all possible orderings of the constituents of the phrase in (3a). This suggests that the rest of the NP apart from the determiner has a flat structure.
a. mọ' ococo Juansi' därsi'
b. mọ' ococo därsi' Juansi'
c. mọ' Juansi' ococo därsi'
d. mọ' därsi' ococo Juansi'
e. mọ' Juansi' därsi' ococo
f. mọ' därsi' Juansi' ococo
'Juan's big frog.'

[elicited]

All the examples of possessors cited so far are what will be termed here 'free' possessors - nominal or pronominal possessors which agree with the gender of the possessed noun and can occur anywhere in the NP except preceding the determiner. There is also a type of bound possessor expression: pronominals which must attach to some NP constituent and do not agree in gender with their head. This can occur with first, second and third person pronominals which have the same form as freestanding pronouns. Compare the examples in (6). In (6a), the pronominal possessor $=m u$ ' 'his' does not exhibit agreement with the head noun. It only agrees with its third person singular masculine antecedent. By contrast, in (6b), which is an example of a free pronominal possessor, the possessor 
This is the accepted version of an article published by John Benjamins in Studies in Language Vol. 41 (3), 660-716. Published online 25 October 2017. Available from: https://doi.org/10.1075/sl.41.3.05rit Accepted version downloaded from SOAS Research Online: https://eprints.soas.ac.uk/25082/

487

agrees with both its antecedent and with the feminine possessed noun, as indicated by the gender agreement suffix $-s i^{\prime}$. The bound possessor in (6a) also necessarily follows the head, while this is not a requirement for free possessors like that in (6b):

$$
\begin{aligned}
& \text { a. ococo }=m u^{\prime} /{ }^{*} m u^{\prime} \text { ococo } \\
& \operatorname{frog}(\mathrm{F})=\text { his } \quad / \text { his } \operatorname{frog}(\mathrm{F}) \\
& \text { b. ococo } m u^{\prime}-s i^{\prime} / m u^{\prime}-s i^{\prime} \text { ococo } \\
& \text { frog(F) his-F / his-F frog(F) } \\
& \text { 'his frog' }
\end{aligned}
$$

[elicited]

The alternation between free and bound pronominal possessors in discourse appears to depend (at least in part) on whether the possessor referent is contrasted with another referent. For example, it is pragmatically infelicitous to use a bound possessor in a context like that in (7), in which the possessor in the answer is contrasted with that in the question:

$$
\begin{aligned}
& \text { a. ¿Cav-i-bu-ti } \quad c a^{\prime} \quad \text { ococo=yu? } \\
& \text { See-CLF-APPL-2SG }>1 \text { SG INTERR frog }(\mathrm{F})=\text { my } \\
& \text { 'Have you seen my frog?' } \\
& \text { b. Jam, cav-e-bi-te ococo } \mathrm{mu}^{\prime}-\mathrm{si}^{\prime} / \text { \#ococo=mu'. } \\
& \text { No see-CLF-APPL-3SG.M.O frog(F) his-F / frog(F)=his } \\
& \text { 'No, I saw HIS frog.' }
\end{aligned}
$$

Bound possessors can also co-occur with both nominal and pronominal free possessors. In (8), bound possessor expressions co-occur with and are coreferential with the free possessor expressions:

$$
\begin{aligned}
& \text { a. Juan-si' ococo }=m u^{\prime} \\
& \text { Juan(M)-F frog(F)=his } \\
& \text { 'Juan's frog' } \\
& \text { b. } m u^{\prime}-s i \text { ' ococo }=m u^{\prime} \\
& \text { his-F frog(F)=his } \\
& \text { 'his frog' }
\end{aligned}
$$

Bound possessors which co-occur with free possessors will be termed 'doubling possessors' here, as they double the features of the free possessor (and possibly function as 
This is the accepted version of an article published by John Benjamins in Studies in Language Vol. 41 (3), 660-716. Published online 25 October 2017. Available from: https://doi.org/10.1075/sl.41.3.05rit Accepted version downloaded from SOAS Research Online: https://eprints.soas.ac.uk/25082/

representations of it in the clause, see Section 7).

The alternation in discourse between possessive phrases featuring both free and bound possessors and those featuring only free possessors is complex, involving a number of contributing semantic and information structural factors, including the relationship of coreference between the subject and the internal possessor and the information structure role of the internal possessor (see Section 6.4).

\subsection{Clitic status of bound possessors}

Bound possessors, determiners and third person singular personal pronouns all have the same form: $m o^{\prime} /=m o^{\prime}$ for feminine and $m u^{\prime}=m u^{\prime}$ for masculine possessors, determiners and pronouns. (9) illustrates the three functions of this element: ${ }^{9}$

$$
\begin{aligned}
& \text { Mu'ca chhi'ba-qui [=mu'vi i'=mu'] } \\
& \text { he HRSY shoot.arrow.CLF-REFL.POSS.M.S }=\text { the.M brother.in.law(M)=his } \\
& \text { 'He shot his brother-in-law with an arrow.' }
\end{aligned}
$$

[svmalc012.264]

In (9), the same form $m u^{\prime}$ fulfils the functions of a third person singular masculine pronoun, a determiner of the masculine head $v . i^{\prime}$ 'brother-in-law' and a bound possessor. Various kinds of evidence suggest that in all of these functions, this element has the morphosyntactic status of a clitic. For example, it exhibits 'promiscuous attachment' (Zwicky \& Pullum 1983: 503), i.e. it is not limited to attaching to a single type of word. In (9), the determiner attaches to the verb and the bound possessor attaches to the possessed noun, while in (10), the pronouns $=m \varphi^{\prime}$ 'she' and $=m i$ 'you' (here realised in a phonologically reduced form as $=m$ ) attach to the hearsay evidential $c a$ and the verb respectively:

\footnotetext{
${ }^{9}$ The first instance of this item is a freestanding pronoun and the other two are enclitics. Each instance is glossed differently to show the different functions of this item., though as a reviewer notes it is likely that it is a single polyfunctional item.
} 
This is the accepted version of an article published by John Benjamins in Studies in Language Vol. 41 (3), 660-716. Published online 25 October 2017. Available from: https://doi.org/10.1075/sl.41.3.05rit Accepted version downloaded from SOAS Research Online: https://eprints.soas.ac.uk/25082/

$$
J u j-y i-^{\prime} \quad c a=\boldsymbol{m} \boldsymbol{\varphi}^{\prime} \text { jäm-i-j } \quad r a^{\prime} j i^{\prime}-s i \tilde{n}-i-t i=\boldsymbol{m} .
$$
accept-CLF-F.S HRSY=she get.ready-CLF-M.S IRR CAUS-shrink-CLF-REFL.M.S=you 'She accepted, "But you need to get ready to shrink yourself." she said.'

[svmalc021-2.151]

This promiscuity can also be seen in the ability of bound possessors to 'float' within the possessive phrase. They can freely attach to any element in the possessive phrase apart from the determiner (see Section 5 on the restriction with the determiner):

$$
\begin{aligned}
& \text { a. mọ' Juan-si' där-si' ococo=mu' shandye-s } \\
& \text { the.F name(M)-F big-F frog }(\mathrm{F})=\mathbf{h i s} \text { green-F } \\
& \text { b. mọ' Juansi' därsi'=mu' ococo shandyes } \\
& \text { c. mọ' Juansi'=mu' därsi' ococo shandyes } \\
& \text { 'Juan's big green frog' }
\end{aligned}
$$

These examples show that it is possible for the bound possessor $=m u^{\prime}$ to attach to the head (11a), to an adjective (11b) or to the free possessor (11c).

Another property of clitics argued for by Zwicky \& Pullum (1983) is that they do not show the kind of morphophonological idiosyncrasies which are commonly associated with affixes. This can be seen in Chimane in the ability of verbal suffixes ending in the high front vowel /i/ to trigger vowel harmony in the verb stem, a property which clitics ending in this vowel do not share. In (12a), the inflectional suffix - $t i^{\prime}$ triggers vowel harmony in the stem (the basic form of this stem is peye-), but in (12b) the pronominal clitic $=m i$ does not trigger this process:
a. $\quad$ Mi $\hat{p} i-y i-t i^{\prime}=y u$. you speak-CLF-2SG $>1 \mathrm{SG}=\mathrm{me}$ 'You talk to me.'
b. Yu $\hat{p} e-y e-y e=m i$. I speak-CLF-1 $\mathrm{SG}>2 \mathrm{SG}=\mathrm{you}$ 'I talk to you.' 
This is the accepted version of an article published by John Benjamins in Studies in Language Vol. 41 (3), 660-716. Published online 25 October 2017. Available from: https://doi.org/10.1075/sl.41.3.05rit Accepted version downloaded from SOAS Research Online: https://eprints.soas.ac.uk/25082/

Zwicky and Pullum also argue that clitics can attach to material which already contains clitics, while affixes cannot exhibit this behaviour. This property can be seen in (13), where the general plural clitic $=$ in can attach to the verb which already hosts the first singular clitic $=y u$ :

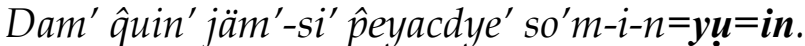

$$
\begin{aligned}
& \text { little now good-F word(F) give-CLF- } 3>1 \mathrm{SG}=\mathbf{m e}=\text { they } \\
& \text { 'Though now they've taught me the Good Word.' }
\end{aligned}
$$

It would be strictly ungrammatical, for example, for the inflectional affix $-n$ to attach to the verb after the first singular clitic in (13), while other clitics like $=$ in can exhibit this behaviour. Taken together, all these properties of the pronominal forms, including in their function as possessors, seem to indicate that they have the status of clitics.

\subsection{Clausal syntax}

There is no case marking of core arguments in Chimane. However, the grammatical functions of subject and object do appear to exist in the language and can be identified by a number of coding and behavioural properties. Subjects in Chimane control subject agreement on intransitive and transitive verbs, they can be the antecedent of anaphoric pronouns in coordinate structures and finite dependent clauses, they cannot be the antecedent of non-reflexive pronouns within clauses, they function as targets in control constructions and they correspond to the addressee in imperative constructions. Objects in Chimane control object agreement on transitive verbs (though object agreement may be absent under certain conditions) and they can be the antecedent of subjects of lower clauses in object control constructions.

Features of subjects and objects of transitive verbs are cross-referenced by a complex verbal agreement paradigm. Depending on the combination of subject and object, one or two suffixes are used to indicate person, number, gender and clusivity features of the two arguments. Some suffixes uniquely identify both arguments, while others do not identify 
This is the accepted version of an article published by John Benjamins in Studies in Language Vol. 41 (3), 660-716. Published online 25 October 2017. Available from: https://doi.org/10.1075/sl.41.3.05rit Accepted version downloaded from SOAS Research Online: https://eprints.soas.ac.uk/25082/

either the subject or object argument, for example the third person object suffixes -te and - ' are used with a number of different subjects, and the third person subject suffixes $-n$ can be used with both first and second person objects, as indicated in Table 2. There are also several cases of syncretism in the paradigm. Table 2 shows combinations of subjects and objects and the forms that are used to identify them. ${ }^{10}$

\begin{tabular}{|c|c|c|c|c|c|c|c|c|}
\hline \multirow{2}{*}{ subject } & \multicolumn{8}{|c|}{ object } \\
\hline & $1 \mathrm{SG}$ & $2 \mathrm{SG}$ & 3SG.M & 3SG.F & 1PL.EXCL & 1 PL.INCL & $2 \mathrm{PL}$ & $3 \mathrm{PL}$ \\
\hline $1 \mathrm{SG}$ & & $-y e$ & \multirow{3}{*}{-te } & \multirow{3}{*}{$-^{\prime}$} & & & $-y a c$ & \multirow{3}{*}{$-\operatorname{csi}\left(-^{\prime}\right)$} \\
\hline $2 \mathrm{SG}$ & $-t i^{\prime}$ & & & & $-t i \hat{c} a^{\prime}$ & $-t i\left(-^{\prime}\right)$ & & \\
\hline 1PL.EXCL & & $-y a c$ & & & & & $-y a c$ & \\
\hline 1PL.INCL & & $-t i \hat{c} a^{\prime}$ & $-j a$ & $-j a-^{\prime}$ & & & $-t i \hat{c} a^{\prime}$ & $-c s e-j a^{\prime}$ \\
\hline $2 \mathrm{PL}$ & $-t i \hat{c} a^{\prime}$ & & -tinte & -tiñe' & $-t i \hat{c} a^{\prime}$ & $-t i\left(-^{\prime}\right)$ & & \multirow{2}{*}{$-\operatorname{csi}\left(-^{\prime}\right)$} \\
\hline 3 & \multicolumn{2}{|c|}{$-n$} & $-t e$ & $-^{\prime}$ & $-n$ & $-\sin ^{\prime}$ & $-n a c$ & \\
\hline
\end{tabular}

Table 2: Chimane transitive agreement paradigm

There are some examples of syncretism in Table 2, for example the -yac suffix which is used to mark $1 \mathrm{SG}>2$ PL and 1 PL.EXCL $>2$ relations. Glottal plosives ${ }^{11}$ identifying feminine subjects are shown in parentheses.

In double object constructions, it is invariably the non-patient-like argument (e.g. the recipient, goal or beneficiary) which controls object agreement on the verb. In (14a), the monotransitive verb $t u$ - 'bring' exhibits object agreement with the feminine patientlike argument. When a primary object argument expressing a beneficiary is added to the argument structure of this verb by the benefactive applicative -ye, as in (14b), the verb exhibits agreement with this argument:

\footnotetext{
${ }^{10}$ The grey cells are combinations which have reflexive meanings. These are indicated by dedicated reflexive verbal morphology and are therefore not considered part of the transitive agreement paradigm.

${ }^{11}$ Glottal plosives are written with an apostrophe $\left.<^{\prime}\right\rangle$ in Chimane orthography.
} 
This is the accepted version of an article published by John Benjamins in Studies in Language Vol. 41 (3), 660-716. Published online 25 October 2017. Available from: https://doi.org/10.1075/sl.41.3.05rit Accepted version downloaded from SOAS Research Online: https://eprints.soas.ac.uk/25082/ 611 to note for the purposes of this study that the language exhibits many features associated 612 with non-configurational syntax, including pragmatically determined word order, discon-

a. Judyeya' mo' qui jejmitidye' tu-i-'=in.
and the.F so cooked.food(F) bring-CLF-3SG.F.o=they

'And they brought hot food.'

b. Judyeya' quica jejmitidye' tu-ye-te=in.

and so HRSY cooked.food(F) bring.CLF-BEN-3SG.M.O=they

'And they brought him hot food.'

[svmalc021-1.021,076]

It would be ungrammatical for the ditransitive verb in (14b) to agree with the patientlike argument jejmitidye' 'hot food'. Thus Chimane exhibits secundative alignment with respect to agreement between verbs and patient- and non-patient-like arguments.

Apart from not being able to control object agreement, the patient-like argument in ditransitive constructions continues to feature other object properties identified above, indicating that it retains the status of an object. In this paper, the object which controls agreement on the verb in a ditransitive construction will be termed the primary object, while the non-agreement-controlling object will be termed the secondary object. The primary object is the 'direct' (i.e. patient-like) object of a monotransitive verb or the indirect' (i.e. non-patient-like object) object of a ditransitive verb or, while the secondary object is the direct/patient-like object of a ditransitive verb (e.g. Bresnan 1982; Dryer 1986).

Finally with respect to background information on Chimane grammar, it is important tinuous constituents and extensive pro-drop (Hale 1983).

\section{Prominent internal possessor construction}

This section provides an introduction to some features of the Chimane PIPC. The crucial feature which differentiates the PIPC from the EPC in Chimane is the fact that the possessor appears to be internal to the phrase headed by the possessed noun, while the external possessor (EP) is by definition external to this phrase. There are several kinds of 
This is the accepted version of an article published by John Benjamins in Studies in Language Vol. 41 (3), 660-716. Published online 25 October 2017. Available from: https://doi.org/10.1075/sl.41.3.05rit Accepted version downloaded from SOAS Research Online: https://eprints.soas.ac.uk/25082/

619 evidence which can be used to show that possessors in PIPCs are internal to the phrase: 620 they exhibit nominal agreement with the possessed noun head of the possessive phrase, 621 they exhibit certain positional restrictions within the phrase, and they cannot undergo syn622 tactic processes like passivization separately from the possessive phrase. These properties ${ }_{623}$ are discussed in more detail in Section 5.2. Before that, a summary of previous work on

\subsection{Previous analyses of PIPCs in Chimane-Mosetén}

${ }_{626}$ Gill (1999b: 105-6) provides some interesting insights into the structure and function of ${ }_{627}$ Chimane PIPCs. He identifies the disjoint relation between subject and possessor, call628 ing the $-b i$ suffix the "another's possession" suffix. He also notes the neutral semantics 629 of the suffix, stating that it may have a benefactive/malefactive meaning, but this is not ${ }_{630}$ necessarily the case. He identifies the alternation in argument structure, stating that the ${ }_{631}$ (formerly direct) object becomes an 'indirect object'. He further notes the morphophono632 logical change which the suffix undergoes preceding other suffixes - see e.g. (22), and 633 the unusual ordering of the suffix in combination with the agreement suffix -cse (3PL.O) $634-$ see e.g. (35).

Sakel (2004) states the -bi suffix in the disjoint PIPC in Mosetén "expresses that an action is carried out to a possession of the person in object position, against the will of this person" (2004: 323), citing the following example:

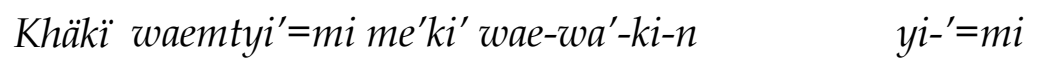
because husband=your like.that beat-PROG-PROG.TR-3>2SG say-F.S=you yi-bi-ti' yäe yij mi. say-POSS.APPL-2SG>1SG my footprint you 'Because your husband is beating you like that, you said, you said to my footprint.'

(Sakel 2004: 323-324)

Sakel does not provide any further explanation of this construction, but the implication 
This is the accepted version of an article published by John Benjamins in Studies in Language Vol. 41 (3), 660-716. Published online 25 October 2017. Available from: https://doi.org/10.1075/sl.41.3.05rit Accepted version downloaded from SOAS Research Online: https://eprints.soas.ac.uk/25082/

644 will. Sakel also notes the unique function of the suffix, stating that unlike other valency645 changing morphology, it does not also double as a verbal classifier, and the unusual or646 dering of the -bi suffix.

\subsection{NP-internal status of possessors in PIPCs}

648 The primary piece of evidence which indicates that possessors in PIPCs are internal is ${ }_{649}$ the fact that they exhibits nominal agreement with the possessed noun, while EPs do not. ${ }_{650}$ This is an obligatory property of possessors in PIPCs; they cannot control agreement 651 on the verb if they do not exhibit nominal agreement with the possessed noun. In (16), 652 the possessor obligatorily exhibits nominal agreement with the feminine possessed noun 660 another clausal element, then this shows that they form a constituent. However, these tests 661 cannot be applied in Chimane, as the language has non-configurational syntax, including 662 free word order and discontinuous constituents. (17a) and (17b) show that possessors and ${ }_{663}$ possessed nouns in PIPCs can occur in either possessed-possessor or possessor-possessed 664 order, while $(17 \mathrm{c})$ shows that possessors can occur discontinuously from the rest of the ${ }_{665}$ possessive NP in the clause. There is no difference in meaning between this sentence and 666 the variants with continuous possessive phrases in (17a) and (17b): 


$$
\begin{aligned}
& \text { a. Yu naij-bi-te } \quad\left[m o_{j}^{\prime} \text { ococo miquityj-si' }\right]_{i} \text {. } \\
& \text { I see-POSS.APPL-3SG.M.O the.F frog(F) boy(M)-F }
\end{aligned}
$$

671 Note that even when the possessor is separated from the rest of the possessive phrase 672 by other clausal elements, it still exhibits nominal agreement with the possessed noun. 673 This indicates that it is still a dependent of the possessed noun, despite being separated 674 from it by other clausal constituents. These examples show that neither the linear order 675 of possessors and possessed nouns in continuous possessive phrases, nor discontinuity of ${ }_{676}$ elements of the possessive phrase in the clause, can be used as tests to determine whether 677 the possessor is internal in PIPCs.

678 However, there are some other types of restrictions on the order of elements within 679 continuous possessive phrases which may provide further evidence that possessors are in680 ternal. Recall from Section 4.1 that possessors can co-occur with determiners in the pos681 sessive phrase (i.e. Chimane is adjectival-genitive) and that the determiner must always

precede all other phrasal constituents. There are also cases in which nominal posses${ }_{683}$ sors occur in a possessive phrase featuring a determiner, and the nominal possessor also 684 combines with its own determiner. An example of this can be seen in (18a), where the masculine possessed noun cas 'knee' combines with the masculine determiner $m u^{\prime}$ and the feminine possessor Isabeltyi' 'Isabel's' combines with the feminine determiner mo'. The possessive phrase in (18a) can be literally translated as '[the knee [the Isabel's]]'. ${ }_{688}$ When possessors combine with their own determiners in a phrase in which the possessed 689 noun also combines with a determiner, the possessor expression can only occur in certain ${ }_{690}$ positions within the phrase. They can occur in a phrase-final position, as in (18a), but they 691 cannot immediately follow the higher level determiner of the entire possessive phrase, as 692 in $(18 b)$ : 
This is the accepted version of an article published by John Benjamins in Studies in Language Vol. 41 (3), 660-716. Published online 25 October 2017. Available from: https://doi.org/10.1075/sl.41.3.05rit Accepted version downloaded from SOAS Research Online: https://eprints.soas.ac.uk/25082/

693
694
695
696
697

$$
\begin{aligned}
& \text { a. Maria täj-je-bi- }{ }_{j} \quad\left[m u^{\prime} \text { cas }\left[=m o^{\prime} \quad \text { Isabel-tyi' }\right]_{j}\right]_{i} \text {. } \\
& \text { Maria(F) touch-CLF-POSS.APPL-3SG.F.O the.M knee(M)=the.F Isabel(F)-M }
\end{aligned}
$$
'Maria touched Isabel's knee.'
b. *Maria täj-je-bi-' [mu' $\left[=m o^{\prime}\right.$ Isabel-tyi'] cas]. Maria(F) touch-CLF-POSS.APPL-3SG.F.O the.M=the.F Isabel(F)-M knee(M) ('Maria touched Isabel's knee.')

[elicited]

698 (18b) shows that it is impossible for the possessor to immediately follow the determiner of 699 the whole possessive phrase when it also combines with its own determiner. The fact that 700 possessors which combine with determiners cannot immediately follow the determiner 701 indicates that possessive phrases in PIPCs have the same internal structure as the posses702 sive phrases discussed in Section 4.1, with the determiner occupying a higher position and 703 the other constituents of the phrase occupying a lower position. These restrictions also 704 provide further evidence that possessors in PIPCs are internal to the possessive phrase.

Another test which may indicate that possessors in PIPCs are internal to the possessive 706 phrase is the fact that they are not accessible to passivization. Dalrymple \& Nikolaeva 707 (2011: 24) state that passivization is not always a clear test of objecthood, as the object 708 of a basic transitive verb does not necessarily correspond to the subject of a passive verb. ${ }_{709}$ However, this test is often used as a diagnostic for objecthood, and can therefore be used 710 to show whether a possessor which controls agreement on the verb is an object or not. ${ }_{711}$ Exactly this kind of test is used by Stump \& Yadav (1988) to show that possessors which 712 control agreement on the verb are internal to the possessive phrase in Maithili (Indo713 Aryan).

714 In Maithili, the verb agrees with the controlling NP in person and honorific grade: the 715 grades are High-Honorific, Honorific, Mid-Honorific, and Non-Honorific (Yadav 1996).

Agreement with the subject is obligatory, but in addition Maithili exhibits a secondary type of agreement. This secondary agreement is optional and is controlled by a non-

subject NP. The grammatical function of this element may vary: in (19a) it is a direct object, in (19b) it is an oblique instrumental object, and in (19c) it is an indirect object. 
This is the accepted version of an article published by John Benjamins in Studies in Language Vol. 41 (3), 660-716. Published online 25 October 2017. Available from: https://doi.org/10.1075/sl.41.3.05rit Accepted version downloaded from SOAS Research Online: https://eprints.soas.ac.uk/25082/

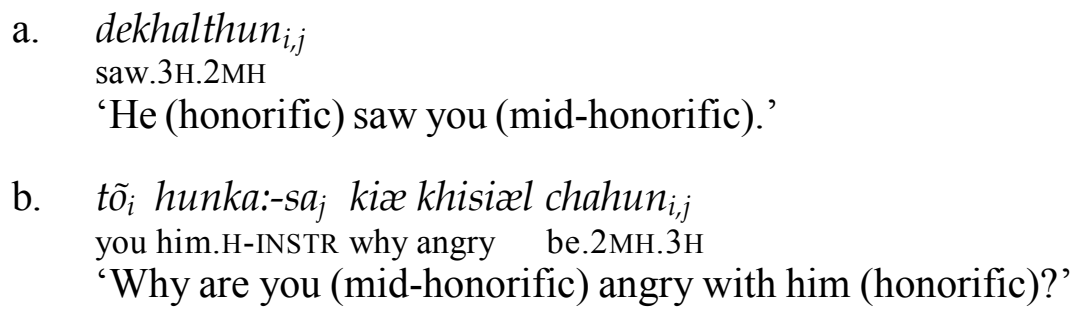

c. $\quad h @ m_{i}$ to-ra $a_{j} \quad k i t a b_{k} d$-@it ch-i@uk

I you.NH-OBJ book give-PTCP be-1.2NH

'I gave a book to you (non-honorific).'

(Stump \& Yadav 1988: 306-7)

Sub-clausal constituents such as objects of postpositions generally cannot control secondary agreement on the verb, but crucially, secondary agreement is possible with the internal possessor, as in the examples in (20) where possessors internal to subject and object arguments control the secondary agreement on the verb:

\section{a. [tohar ba:bu $_{i}$ Mohan-ke $e_{k}$ dekhalthun ${ }_{i, j}$ \\ your father Mohan-OBJ saw.3H.2NH \\ 'Your (non-honorific) father saw Mohan.'}

b. $\quad o_{i} \quad$ [tora: $k$ ba:p-ke $]_{j}$ dekhalthun ${ }_{i, k}$

he.H your.NH father-OBJ saw.3H.2NH

'He saw your (non-honorific) father.' $\quad$ (Stump \& Yadav 1988: 309, 317)

In (20a), the verb agrees with the possessed noun ba:bu 'father' and the possessor tohar 'your', both of which are internal the subject NP. In (20b), the verb agrees with the subject $o$ 'he' and the possessor tora: 'your' which is internal to the object NP.

The only possible passive for (20b) is (21a), where the subject corresponds to the entire possessive phrase which bears the object function in (20b). Example (20b) cannot have a passive variant such as (21b) whose subject is the former possessor:

a. $\quad$ tohar $_{j}$ ba:p $]_{i}$ dekhal gel

your father seen went.3NH

'Your (non-honorific) father was seen.'

b. *tõ ba:p(-ke) dekhal gele

you.NOM father-OBJ seen went.2NH

('Your (non-honorific) father was seen.')

(Stump \& Yadav 1988: 317) 
This is the accepted version of an article published by John Benjamins in Studies in Language Vol. 41 (3), 660-716. Published online 25 October 2017. Available from: https://doi.org/10.1075/sl.41.3.05rit Accepted version downloaded from SOAS Research Online: https://eprints.soas.ac.uk/25082/

In (21a), the auxiliary verb gel exhibits agreement with the possessive phrase headed by the the third person non-honorific possessed noun ba:p 'father'. The possessor also 746 stands in the genitive case in (21a). An example like (21b), where the possessor stands 747 in the nominative and the auxiliary exhibits agreement with the possessor, is ungrammat748 ical. Stump \& Yadav argue that this shows that the possessor which controls secondary 749 agreement in (20b) does not bear an argument function in the clause, but is internal to the possessive phrase headed by the possessed noun.

Passivization of PIPCs is different in Chimane, as the possessor appears (at least on 752 initial inspection) to be able to function as the subject of the passive, as shown in (22a), ${ }^{12}$ 753 where the passive verb exhibits subject agreement with the feminine possessor. ${ }^{13}$ However, in a similar way to Maithili, where the possessor must stand in the genitive case, 755 in Chimane, the possessor must exhibit nominal concord with the head noun in this construction, as shown by the ungrammaticality of $(22 b)$ :

${ }_{761}$ The fact that possessors must exhibit nominal concord with the possessed noun in passive 762 PIPCs provides some indication that they cannot function as independent arguments in 763 syntactic processes such as passivization. This provides further evidence that possessors in PIPCs are internal to the possessive phrase.

The tests outlined here all indicate that possessors in PIPCs are internal to the posses766 sive phrase just like their counterparts in the defaul IPC construction. Before moving on to look at potential analyses of PIPCs and then the proposed analysis of the construction,

\footnotetext{
${ }^{12}$ The applicative suffix $-b i$ is realised as $-b u$ in these examples due to a morphophonological rule which entails that high vowels in verbal suffixes are lowered when they are followed by other suffixes which also feature a high vowel.

${ }^{13}$ In fact, as argued later, it is not the internal possessor which functions as the subject of the passive verb in (22a), but rather an external proxy of the internal possessor.
} 
This is the accepted version of an article published by John Benjamins in Studies in Language Vol. 41 (3), 660-716. Published online 25 October 2017. Available from: https://doi.org/10.1075/sl.41.3.05rit Accepted version downloaded from SOAS Research Online: https://eprints.soas.ac.uk/25082/

one other distinctive aspect of it - the - bi suffix which occurs on the verb - is considered in Section 5.3.

\subsection{Applicative -bi}

771 In Chimane, when non-patient-like arguments control object agreement on semantically 772 monotransitive verbs, applicative morphology also typically appears on the verb. This is 773 also the case in the PIPC; when the non-patient-like possessor controls object agreement 774 on the verb instead of the possessive phrase headed by the the patient-like possessed noun, 775 the $-b i$ suffix obligatorily occurs. Therefore this suffix appears to have an applicative-like 776 function. However, applicatives are typically a means by which an adjunct or peripheral 777 argument can function as a core object argument (Peterson 2007). This 'promotion' of 778 adjunct or peripheral argument to object function also results in some rearrangement of 779 the mapping between grammatical functions and semantic roles, with the applied object 780 typically bearing a non-patient-like role like beneficiary, recipient or goal etc. This def781 inition of applicatives has two key components. First, that the applied argument is an 782 object, and second that it maps to some semantic role in the argument structure of the 783 verb. On initial inspection, PIPs do not appear to meet either of these criteria, as they do ${ }_{784}$ not appear to function as independent arguments in the clause, and it is not clear whether 785 they always map to a semantic role distinct from that borne by the possessed noun. These two properties are considered in turn here.

787 It is useful to contrast the - $b i$ suffix with other more typical examples of applicatives 788 in the language. For example, the benefactive applicative is a classical object-inserting 789 operation. In benefactive applicative constructions, an object is inserted into the argument 790 structure of the verb which maps to the beneficiary role. This operation is illustrated by 791 the default transitive construction in (23a) and the benefactive applicative construction in 792 (23b): 
This is the accepted version of an article published by John Benjamins in Studies in Language Vol. 41

(3), 660-716. Published online 25 October 2017. Available from: https://doi.org/10.1075/sl.41.3.05rit

Accepted version downloaded from SOAS Research Online: https://eprints.soas.ac.uk/25082/

793
794
795
796
a. Yuquev-e-' ococo (miquity=dye-s).
I look.for-CLF-3SG.F.O frog(F) boy(M)=BEN-F
'I looked for the frog (for the boy).'
b. Yuquev-e-ye-te ococo miquity.
I look.for-CLF-BEN-3SG.M.o frog(F) boy(M)
'I looked for the frog for the boy.'

[elicited]

797 In (23a), the beneficiary is expressed by an oblique nominal miquitydyes 'for the boy' ${ }^{14}$ 798 The patient-like argument ococo 'frog' controls object agreement on the verb and is there799 fore assumed to bear the object function. In (23b), the verb exhibits the benefactive ap800 plicative suffix -ye and the beneficiary miquity 'boy' controls object agreement on the 801 verb. It is therefore assumed that the latter functions as the primary object while the pa802 tient ococo 'frog' functions as the secondary object of the derived ditransitive verb. Both 803 the object inserting property of the applicative and the alternative mapping between argu804 ment structure and grammatical functions can be observed in this construction versus the 805 default.

806 Applying these properties to the -bi suffix in PIPCs, the fact that the possessor con807 trols object agreement seems to indicate that the suffix enables it to function in a similar 808 way to the beneficiary in benefactive applicative constructions, taking over the primary

object function and demoting the possessive phrase headed by the possessed noun to 810 a secondary object status. However, unlike in the benefactive applicative construction, 811 where the absence of the benefactive marking on the nominal bearing the beneficiary role 812 clearly indicates its promotion to argument status, it is not clear how the -bi suffix enables 813 the possessor to function as the primary object in the PIPC, since there is no comparable 814 change in its marking with respect to its counterpart in the default construction. Examples 815 (1a) and (1c) are repeated in (24) to illustrate this point:

\footnotetext{
${ }^{14}$ The benefactive $=d y e$ - in (23a) agrees with the feminine gender of the object ococo 'frog'. It is not entirely clear why this is the case. Sakel (2002: 294) states that "...the benefactive case marking might agree in gender with an established topic...", while in the Mosetén grammar she states that "the benefactive element ... can be interpreted as a secondary predication of the object noun phrase" (2004: 110-11). Both these proposals are dubious and are not backed up by any further argumentation. Further research is required to show why this agreement pattern occurs.
} 

'Juan touched Sergio's hand.'
b. Juan täj-je-bi-te [un $_{j} \quad m u^{\prime}$ Sergio $\left._{j}-s\right]_{i}$. Juan(M) touch-CLF-POSS.APPL-3SG.M.O hand(F) the.M Sergio(M)-F 'Juan touched Sergio's hand.'

Unlike the beneficiary in the benefactive applicative construction, the possessor in the

PIPC exhibits the same marking as its counterpart in the default transitive construction, 822 and as has been shown in Section 5.2, various kinds of evidence show that the possessor 823 is internal to the possessive phrase in the PIPC.

As well as not exhibiting the marking usually associated with independent arguments, 825 it is also not clear whether PIPs always map to a semantic role different from the possessed 826 ${ }_{827}$ possessor can have a beneficiary or maleficiary role in the PIPC; he notes that the action 828 expressed by the verb is done "against [the possessor referent's] consent" (1999b: 125). 829 Sakel (2004) also states for the construction in Mosetén that the action is done "against 830 the will of [the possessor referent]" (2004: 323). While this beneficiary/maleficiary role ${ }_{831}$ may be assigned to the possessor in some cases, it is important to note that this is not the 832 only possibility, and in many cases it is not clear that PIPs are assigned any semantic role 833- (Gill 1999b: 105) also makes this observation. Some examples which help to illustrate 834 this point are considered here.

Shklovsky (2012) compares a PIPC-like construction in Tseltal (Mayan) with certain well-established features of EPCs, and makes a series of observations from which he ${ }_{837}$ concludes that possessors are not assigned a semantic role in the Tseltal construction. In ${ }_{838} \mathrm{EPCs}$, some kind of 'affectee' role is often assigned to the EP, and the integration of the EP into the clausal syntax is the means by which some languages signal this role (cf.

Shibatani 1994). Shklovsky shows that this is not the case in Tseltal, and his tests can 841 also be usefully applied to the PIPC in Chimane. First of all, the construction can occur 842 with so-called 'non-affecting' predicates like 'see'. Example (16), repeated here in (25), 
This is the accepted version of an article published by John Benjamins in Studies in Language Vol. 41 (3), 660-716. Published online 25 October 2017. Available from: https://doi.org/10.1075/sl.41.3.05rit Accepted version downloaded from SOAS Research Online: https://eprints.soas.ac.uk/25082/

shows that PIPs can also occur with non-affecting predicates in Chimane.

$$
\begin{aligned}
& \text { Yu naij-bi-teró ococo Juan-si' } \\
& \text { I see-Poss.APPL-3sg.m.o the.F frog(F) Juan(M)-F } \\
& \text { 'I saw Juan's frog.' }
\end{aligned}
$$

[elicited]

PIPs can also be inanimate objects, as in (26) where the possessor mesa 'table' is an inanimate object and yet can control agreement on the verb:

$$
\begin{aligned}
& \text { Juan cäts-je-bi-' yuj mesa-s } \\
& \text { Juan(M) hack-CLF-POSS.APPL-3sG.F.O leg(F) table(F)-F } \\
& \text { 'Juan cut the table's leg.' }
\end{aligned}
$$

[elicited]

EPCs are also often limited to occurring with certain types of possessors (Payne \& Barshi 1999). There is no such restriction with PIPCs in Chimane; any kind of possessive relationship can feature a PIP, including alienable possessors. Possessors of body parts 53 (27a), kin (27b), alienable possessions (27c), and even non-specific possessors (27d) can 84 all occur in the construction.

$$
\begin{aligned}
& \text { a. Juan ciat-bi-te un' mu' Sergio-s } \\
& \text { Juan(M) cut-POSS.APPL-3sG.M.o hand(F) the.M Sergio(M)-F } \\
& \text { 'Juan cut Sergio's hand.' }
\end{aligned}
$$
b. Juan pus-je-p-te Sergio-s voji' $=m u^{\prime}$ Juan(M) kiss-CLF-POSS.APPL-3SG.M.O Sergio(M)-F sister(F)=his 'Juan kissed Sergio's sister.'

$$
\begin{aligned}
& \text { c. Maria jäc-bi-' ts îj mọ' achu-ty } \\
& \text { Maria(F) remove-POSS.APPL-3SG.F.O louse(M) the.F } \operatorname{dog}(\mathrm{F}) \text {-M } \\
& \text { 'Maria picked the dog's fleas.' } \\
& \text { d. Maria quev-bi-te mọ' majitidye' son-si' } \\
& \text { Maria(M) look.for-POSS.APPL-3SG.M.O the.F love(F)-M man(M)-F } \\
& \text { 'Maria was looking for a (non-specific) man's love.' }
\end{aligned}
$$

${ }_{863}$ This is contrast to the Chimane EPC, which appears to be limited to occurring with body 864 part possessive relationships (further research is required to definitively show this but ${ }_{865}$ EPCs only occur with body part relationships in my corpus). Example (1b) is repeated in 866 (28) to illustrate the Chimane EPC: 


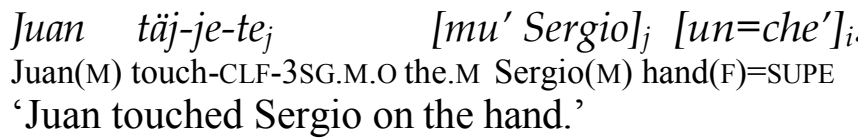

[elicited]

EPCs are also sometimes limited to only occurring with dynamic verbs (Payne \& Barshi 1999). Again this is not the case with PIPs in Chimane, which can occur even with highly stative predicates such as $c h . i-$ 'know':

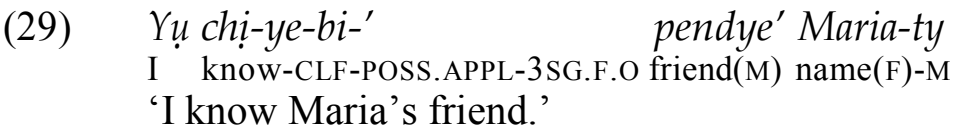

874 These examples indicate that while PIPs may be assigned an 'affectee' type role in some 875 cases, this does not appear to be a definitional function of the $-b i$ suffix. I will therefore 876 follow Shklovsky's analysis of Tseltal and analyse the -bi suffix as a non-semantic role877 assigning applicative.

878 These data indicate that while the - $b i$ suffix clearly has some role to play in enabling 879 the PIP to control object agreement, it does not have the typical properties associated with 880 applicatives, as the applied object appears to correspond to an internal possessor which does not appear to be associated with any particular semantic role.

The observations made in this section lead me to conclude that the possessor in the

PIPC is internal to the possessive phrase, and that the applicative $-b i$ increases the va884 lency of the verb such that the internal possessor is promoted to the primary agreement885 controlling object function in the clause. However, there is no change in the marking of 886 the possessor despite this promotion, and the possessor is also not necessarily assigned 887 a semantic role different from the possessive phrase which it is internal to. This there888 fore begs the question of how this construction should be analysed, as crosslinguistically 889 (and also everywhere else in Chimane grammar) NP-internal elements typically cannot 890 bear argument functions or participate in clause-level syntactic processes like predicate891 argument agreement. Some potential analyses of the PIPC are considered in Section 6, before the proposed analysis is set out in Section 7. 
This is the accepted version of an article published by John Benjamins in Studies in Language Vol. 41 (3), 660-716. Published online 25 October 2017. Available from: https://doi.org/10.1075/sl.41.3.05rit Accepted version downloaded from SOAS Research Online: https://eprints.soas.ac.uk/25082/

\section{${ }_{893} 6$ Potential analyses}

${ }_{894}$ As outlined in Section 5.2, various types of evidence indicate that an analysis in which the ${ }_{895}$ possessor itself is external to the possessive phrase is not appropriate for the PIPC. There 896 are several other potential analyses of the construction which have been proposed for 897 similar or related constructions in other languages. The possibilities can be summarized as follows:

a. The possessor takes on the function of the head of the possessive phrase (headdependent reversal - Dixon 2000).

b. The possessor is not the head but occurs in a privileged syntactic position in the possessive phrase which enables it to function as the argument (prominent NP-internal position - Nikolaeva 2005;2014a).

c. The head of the possessive phrase is incorporated into the verb (incorporation Shklovsky 2012).

d. The possessor is internal to the possessive phrase but has an external representation or 'proxy' in the clause which functions as the argument (mediated locality - Polinsky 2003; Le Sourd 2014).

e. Predicate-'argument' agreement does not correlate one-to-one with grammatical functions but is pragmatically determined and can be controlled by topical or topic-worthy non-arguments including internal possessors (topic agreement Dalrymple \& Nikolaeva 2011).

${ }_{913}$ Apart from the final possibility, the differences between these potential analyses all centre 914 around the status, position and grammatical function of the internal possessor. In terms of 915 its status, it is either the head of the phrase or not. In terms of its position, it is either in a ${ }_{916}$ prominent syntactic position in the phrase or not, and either has a clause-level representa917 tion or not. In terms of its grammatical function, it (or its external representation if it has 918

one) is either an argument of the verb or not. If the possessor is neither the head of the 
This is the accepted version of an article published by John Benjamins in Studies in Language Vol. 41 (3), 660-716. Published online 25 October 2017. Available from: https://doi.org/10.1075/sl.41.3.05rit Accepted version downloaded from SOAS Research Online: https://eprints.soas.ac.uk/25082/

${ }_{919}$ phrase, nor has a privileged syntactic position in the phrase nor a clause-level proxy, then 920 it is necessary to consider the final possibility - that internal possessors can control agree921 ment when they are semantically or information structurally prominent, and this is the 922 only factor that affects agreement. ${ }^{15}$ The data offer little in the way of evidence for some 923 of the potential analyses listed above, so these can be relatively uncontroversially rejected. ${ }_{924}$ However, there are two potential analyses of the PIPC for which there does seem to be 925 some supporting evidence: that the internal possessor has a clause-level representation, 926 and that agreement is sensitive to the topicality of the possessor.

927 In the following sections, each of the potential analyses listed above is considered in ${ }_{928}$ turn. In many cases, these analyses have been proposed for other languages which exhibit ${ }_{929}$ PIPCs or related constructions, so the relevant data and arguments from those studies is considered alongside (mostly elicited) data from Chimane.

\subsection{Head-dependent reversal}

${ }_{932}$ In Jarawara (Arawan), internal possessors can control agreement on the verb under certain ${ }_{933}$ circumstances (Dixon 2000). For example, in the following text fragment, the verb agrees ${ }_{934}$ with first person plural topic in all four clauses, even though the latter corresponds to the

$$
\begin{aligned}
& \text { a. mee-inamati era } \varnothing \text { wete na } \\
& \text { PL-spirit us.INCL 3SG.A bind AUX.F } \\
& \text { 'the evil spirits bound us (with string)' } \\
& \text { b. [ee } \boldsymbol{e}_{j} \text { mano }_{i} \varnothing \text { soki } \boldsymbol{k a s a}_{j} \\
& \text { our.INCL(F) arm(M) 3.INAN.S tie ALL.AT.ONCE.F } \\
& \text { 'our arms were tied together' } \\
& \begin{array}{ll}
\text { c. } & {\left[\boldsymbol{e e}_{j} \quad \text { iso }\right]_{i} \varnothing \quad \text { soki } \boldsymbol{k a s a}_{j}} \\
\text { our.INCL(F) leg(M) } & \text { 3.INAN.S tie } \\
\text { 'our legs were tied together' } & \text { ALL.AT.ONCE.F }
\end{array}
\end{aligned}
$$

\footnotetext{
${ }^{15}$ Semantics and information structure can also play a role in the other potential analyses, but only indirectly through syntax.

${ }^{16}$ In all the examples in (30), the feature of the first person plural pronoun which is expressed on the verb is its feminine gender. However, this does not mean that the referents are necessarily feminine. According to Dixon all pronouns in Jarawara are feminine.
} 
This is the accepted version of an article published by John Benjamins in Studies in Language Vol. 41 (3), 660-716. Published online 25 October 2017. Available from: https://doi.org/10.1075/sl.41.3.05rit Accepted version downloaded from SOAS Research Online: https://eprints.soas.ac.uk/25082/ ${ }_{947}$ Jarawara is determined by its head. In alienable possessive NPs, the head is the possessed 948 noun, but according to Dixon, in inalienable possessive NPs like those in (30b) and (30c), 949 the possessor is the head. An argument in favour of this analysis comes from adjectival 950 agreement in the possessive phrase. For example, in (31), the adjective bite 'small' agrees 951 with the feminine gender of the first person plural pronoun $e e$ rather than the masculine 960 they can in Jarawara. The issue is slightly clouded by the fact that nominal agreement in ${ }_{961}$ Chimane is only in gender, and only third person nominals and pronominals have an (in962 herent) gender feature. ${ }^{17}$ It is therefore possible for a nominal (and therefore necessarily ${ }_{963}$ third person) PIP to be modified by an adjective. However, there is a very clear distinc964 tion in the meaning of sentences in which adjectives modify PIPs versus those in which 965 they modify possessed nouns. For example, in (32a), the adjective där- 'big' can only be 966 interpreted as modifying the possessed noun, while in (32b) it can only be interpreted as

\footnotetext{
${ }^{17}$ First and second person pronouns also have a context-dependent gender feature which is determined by the sex of the speech act participants.
} 
This is the accepted version of an article published by John Benjamins in Studies in Language Vol. 41

(3), 660-716. Published online 25 October 2017. Available from: https://doi.org/10.1075/sl.41.3.05rit Accepted version downloaded from SOAS Research Online: https://eprints.soas.ac.uk/25082/

modifying the PIP:

$$
\begin{aligned}
& \text { a. Yu naij-bi-te [mọ' ococo där-si' [miquity-si']]. } \\
& \text { I see-POSS.APPL-3SG.M.O the.F frog(F) big-F boy(M)-F } \\
& \text { 'I saw the boy's big frog.' / *'I saw the big boy's frog.' } \\
& \begin{array}{l}
\text { b. Yu naij-bi-te } \\
\text { I see-Poss. ococo [miquity-si' där-tyi']]. }
\end{array} \\
& \text { 'I saw the big boy's frog.' / *'I saw the boy's big frog.' }
\end{aligned}
$$

972 Apart from the restriction that the determiner must precede all other constituents of the ${ }_{973}$ possessive phrase, the other constituents of the phrase in (32a) can occur in any order, as 974 shown in Section 4.1. However, when the adjective modifies the possessor, as in (32b), 975 there is a preference for the adjective to either precede or follow the possessor. This 976 indicates that this adjective is internal to the NP headed by the possessor. In any case, 977 the starred interpretation of (32b) is impossible, which shows that the possessor cannot 981 initions developed by Zwicky (1985), Fraser et al. (1992) list the following properties of 982

control agreement on an adjective which modifies the head noun.

Beyond the inability of PIPs to control agreement on adjectives which modify the heads which are important in manylanguages: ${ }^{18}$

a. The constituent is the semantic argument.

b. The constituent is the determinant of agreement.

c. The constituent is the morphosyntactic locus (of case marking).

d. The constituent is subcategorized by the verb.

e. The constituent is the distributional equivalent of its phrase.

f. The constituent is obligatory.

(Fraser et al. 1992: 1-2)

Taking each of these properties in turn, it is possible to show more definitively that the possessor is not the head of the possessive phrase in PIPCs. First of all, the possessor

\footnotetext{
${ }^{18}$ The full list also includes other properties which are not relevant to the present discussion.
} 
This is the accepted version of an article published by John Benjamins in Studies in Language Vol. 41 (3), 660-716. Published online 25 October 2017. Available from: https://doi.org/10.1075/sl.41.3.05rit Accepted version downloaded from SOAS Research Online: https://eprints.soas.ac.uk/25082/

is not the semantic argument of the verb. As discussed in Section 5.3, it is possible for the possessor to bear a beneficiary- or maleficiary-like role in the PIPC, but this is by no means a requirement and it is more common that the possessor is not assigned a semantic role different from that assigned to the possessive phrase headed by the possessed noun. Second, as has just been discussed, it is clear from the example in (32) that the possessor is not the determinant of nominal agreement in the possessive phrase. This property is retained by the possessed noun. However, the possessor is the determinant of agreement on the verb. This is an important point which I will return to later. The third property, that the head is the morphosyntactic locus of case marking, cannot be applied in Chimane as there is no case marking of core arguments and PIPs can only control object agreement when they function as core arguments. However, it is possible for possessors to host a case-like clitic when the possessive phrase bears an oblique function, as in (33) where the possessor, rather than the possessed noun, bears the locative $=y a^{\prime}$ :

$$
\begin{aligned}
& \text { ¿Jam buty mi ji-yi Juan-si'=ya' aca'=mu'? } \\
& \text { NEG Q you pass-CLF.M.S Juan(M)-F=LOC house }(\mathrm{F})=\text { his } \\
& \text { 'Haven't you passed by Juan's house?' }
\end{aligned}
$$

[elicited]

However, this appears to be a general property of phrasal morphosyntax; when a head combines with a modifier, there is a distinct preference for the modifier to host the caselike clitic. The examples in (34) show the superessive $=c h e^{\prime}$ being hosted by adjectives and numerals respectively:

\section{a. Mọ' därä' jọ́cha-i-' poroma-s=che' aca' tŝọ-i-'.} the.F tree(F) fall-CLF-F.S old-F=SUPE house(F) land-CLF-F.S 'The tree fell on the old house.'

$$
\begin{aligned}
& \text { b. Yu coosh-i pärä'=che' jubij. } \\
& \text { I sleep-CLF.M.s two=suPE bed(F) } \\
& \text { 'I sleep on two beds.' }
\end{aligned}
$$

These examples indicate that the locus of case marking cannot be taken as evidence that a phrasal constituent is the head in Chimane. 
This is the accepted version of an article published by John Benjamins in Studies in Language Vol. 41 (3), 660-716. Published online 25 October 2017. Available from: https://doi.org/10.1075/sl.41.3.05rit Accepted version downloaded from SOAS Research Online: https://eprints.soas.ac.uk/25082/

The fourth property of heads is that they are subcategorized by the verb. While the verb in the PIPC does exhibit object agreement with the possessor, and this is strong evidence that the possessor functions as the object of the verb, it seems that the possessive phrase headed by the possessed noun is also subcategorized by the verb as a secondary object (see Section 6.4 for further discussion of this point). Fixth, the possessed noun does appear to be the distributional equivalent of the possessive phrase. This can be seen in repetitions of similar sentences featuring PIPCs in naturalistic speech. For example, in (35), the anaphor of the possessive phrase in (35a) is the possessed noun and not the possessor in (35b):

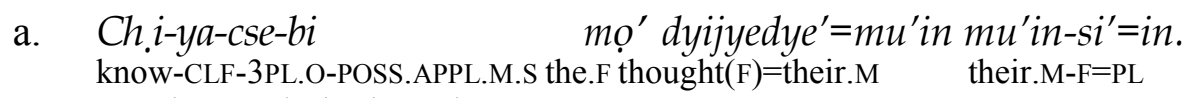
'He knew their thoughts.'

b. Ch.i-ya-cse-bi mo' dyijyedye' paj qui jam know-CLF-3PL.O-POSS.APPL.M.S the.F thought(F) so.that so NEG $j i^{\prime}-d y \ddot{a}-q u e-t e=i n$. CAUS-stop-CLF-3SG.M.O=they 'He knew (their) thoughts so they wouldn't be able to stop him.'

[svfemr002.029-030]

The possessive referent 'their thoughts' is realized by a full possessive phrase mo. ' $d y$ ijyedye' mu'in mu'in-si' in in (35a), but only by the possessed noun mo. 'dyijyedye' in $(35 \mathrm{~b}),{ }^{19}$ indicating that the latter is the distributional equivalent of the phrase. Finally, the possessed noun does appear to be obligatory in PIPCs. While it is possible for the possessor to be omitted in a PIPC, as in (35b), it is not possible to omit the possessed noun in a non-elliptical context.

The fact that the possessed noun retains all of these properties in the PIPC seems to imply that the possessor does not function as the head of the possessive phrase in PIPCs, as Dixon argues for Jarawara. Therefore a head-dependent reversal-type analysis does not appear to be appropriate for the construction.

\footnotetext{
${ }^{19}$ In (35b), the agreement is with the null possessor rather than the possessed noun.
} 
This is the accepted version of an article published by John Benjamins in Studies in Language Vol. 41 (3), 660-716. Published online 25 October 2017. Available from: https://doi.org/10.1075/sl.41.3.05rit Accepted version downloaded from SOAS Research Online: https://eprints.soas.ac.uk/25082/

\subsection{Structurally prominent NP-internal possessor}

Another possibility is that the possessor does not head the possessive phrase but has a prominent or peripheral structural position within it, and this peripheral position is what makes it 'visible' to predicate-argument agreement. There are no analyses of PIPCs along these lines, but there are analyses of other types of constructions which exhibit unusual behaviour in terms of agreement between elements in different syntactic domains. For example, this type of analysis has been proposed for a type of long-distance agreement (LDA) construction in Tsez (Nakh-Daghestanian) by Polinsky \& Potsdam (2001). In Tsez, a verb can agree with an argument in a subordinate clause, as in (36b), where the verb -ixyo 'know' exhibits agreement with the class III nominal magalu 'bread' which functions as an argument in the subordinate clause.

a. enir $r_{i}\left[u \check{z} \bar{a}_{k} \text { magalum } \quad b \bar{a} c^{\prime} \text { ruti }\right]_{j} r_{j}$-iyxo mother [boy bread.III.ABS ate].IV IV-know

b. enir ${ }_{i} \quad\left[u z \bar{a}_{k} \boldsymbol{m a g a l u}_{m} \quad b \bar{a} c^{\prime}{ }^{\prime} u t i\right]_{j} \boldsymbol{b}_{m}-i y x o$ mother [boy bread.III.ABS ate].IV III-know 'The mother knows the boy ate the bread.'

(Polinsky \& Potsdam 2001: 584)

In (36a), the verb agrees with the class of the entire subordinate clause which functions as its complement, as shown by the agreement prefix $r$-. (36b) shows that it is also possible for the verb to agree with an argument internal to this subordinate clause, here the object of the verb in the subordinate clause magalu 'bread'. This kind of agreement pattern is comparable to PIPCs, i.e. constructions in which verbs agree with internal possessors, because in both cases the agreement target (the verb) and controller (the argument in the subordinate clause or the possessor) are not in the same local domain. Polinsky \& Potsdam argue that the argument in the subordinate clause can control predicate-argument agreement when it is syntactically 'close' to the verb. Their proposal involves movement of the agreement controller to a peripheral position (specifically the specifier position of a Topic Phrase in the left periphery of the subordinate clause) which is sufficiently close 
This is the accepted version of an article published by John Benjamins in Studies in Language Vol. 41 (3), 660-716. Published online 25 October 2017. Available from: https://doi.org/10.1075/sl.41.3.05rit Accepted version downloaded from SOAS Research Online: https://eprints.soas.ac.uk/25082/

to the verb in the matrix clause as to make the controller 'visible' to the verb.

In a similar way, Nikolaeva (2014a) argues that only internal possessors which occupy a structurally prominent position within the NP can participate in clause-level syntactic processes in Tundra Nenets (Uralic). In that language, the possessor can optionally control possessive agreement on the possessed noun, and in such cases, it appears to be associated with a different structural position within the NP. This can be seen in the linear order of constituents in possessive phrases. Consider the examples in (37). When the possessed noun does not agree with the possessor, the latter must follow determiners such as the demonstrative, as in (37a), where the possessor Werah 'Wera's' follows the determiner $t^{\prime} u k u^{\circ}$ 'this'. When the possessed noun does agree with the possessor, the latter must precede the determiner, as in (37b). (37c) shows that the possessor cannot follow the determiner if the possessed noun exhibits agreement, and (37d) shows that the possessor cannot precede the determiner if the possessed noun does not exhibitagreement.

$$
\begin{aligned}
& \text { a. } t^{\prime} u k u^{\circ} \text { Wera- } h \text { ti } \\
& \text { this Wera-GEN reindeer } \\
& \text { 'this reindeer of Wera's' } \\
& \text { b. Wera- } h \text { t'uku' te-da } \\
& \text { Wera-GEN this reindeer-3sG } \\
& \text { 'this reindeer of Wera's' } \\
& \text { c. * } t^{\prime} u k u^{\circ} \text { Wera- } h \text { te- } d a \\
& \text { this Wera-GEN reindeer-3sG } \\
& \text { ('this reindeer of Wera's') } \\
& \text { d. *Wera- } h \text { t'uku' } t i \\
& \text { Wera-GEN this reindeer } \\
& \text { ('this reindeer of Wera's') }
\end{aligned}
$$

Nikolaeva shows that possessors which control agreement on the possessed noun exhibit a range of morphosyntactic properties which indicate that their functional prominence is mirrored by their syntactic prominence.

There does not seem to be any evidence for this type of configuration in Chimane. While PIPs can occur in positions discontinuous from the rest of the possessive phrase due to the non-configurational nature of Chimane syntax, my consultants found PIPCs in 
This is the accepted version of an article published by John Benjamins in Studies in Language Vol. 41 (3), 660-716. Published online 25 October 2017. Available from: https://doi.org/10.1075/sl.41.3.05rit Accepted version downloaded from SOAS Research Online: https://eprints.soas.ac.uk/25082/

which a free PIP immediately precedes the determiner to be strange:

(38)

$$
\begin{aligned}
& \text { ?Maria täj-je-bi-' Isabel-tyi' } m u^{\prime} \text { cas. } \\
& \text { name(F) touch-CLF-POSS.APPL-3sG.F.O name(F)-M the.M knee(M) }
\end{aligned}
$$

('Maria touched Isabel's knee.') [elicited]

It should be noted that there was some disagreement amongst the consultants about this construction, with one saying that it is acceptable. This difference in opinion may be attributed to a difference in the interpretation of the possessive phrase as continuous or discontinuous. The consultants were however unanimous in their judgements of constructions in which the PIP controls agreement on the head nominal, which they considered strictly ungrammatical:

$$
\begin{aligned}
& \text { *Maria täj-je-bi-' } \text { mu' cas-si' Isabel-tyi'. }^{\prime} \text { name(F) touch-CLF-POSS.APPL-3SG.F.O the.M knee(M)-F name(F)-M }
\end{aligned}
$$
('Maria touched Isabel's knee.')

These judgements seem to indicate that the possessor does not have a privileged syntactic status within the phrase, and therefore the idea the possessor can control predicateargument agreement because it is syntactically 'closer' to the verb does not seem to be applicable to the PIPC in Chimane.

\subsection{Incorporation}

Another analysis which has been proposed for a very similar construction to the Chimane PIPC is that the possessor is incorporated into the verb. The term 'incorporation' is used here in the transformationalist sense of an adjoining of two functional heads. This analysis is developed by Shklovsky (2012) to account for what he terms the external possession construction in Tseltal. In Tseltal, agreement between the verb and an internal possessor is possible in the presence of an applicative, just as in Chimane. The regular transitive construction is shown in (40a) and the construction in which the verb agrees with the internal possessor is shown in (40b): 
This is the accepted version of an article published by John Benjamins in Studies in Language Vol. 41 (3), 660-716. Published online 25 October 2017. Available from: https://doi.org/10.1075/sl.41.3.05rit Accepted version downloaded from SOAS Research Online: https://eprints.soas.ac.uk/25082/

(40)

$$
\begin{aligned}
& \text { a. } \quad \text { lah } a-w e^{\prime} \quad\left[k_{j}-w a j\right]_{i} \\
& \text { PFV ERG2-eat.ABS3 my-tortilla } \\
& \text { 'You ate my tortilla.' } \\
& \text { b. lah a-we'-bon } \quad\left[\boldsymbol{k}_{j} \text {-waj }\right]_{i} \\
& \text { PFV ERG2-eat-APPL.ABS1 my-tortilla } \\
& \text { 'You ate my tortilla.' }
\end{aligned}
$$

Working in the minimalist framework, Shklovsky assumes that applicatives project their own phrase. He argues that the possessive phrase is incorporated in this phrase, meaning that the internal possessor can control the absolutive agreement on the verb.

While I do not follow Shklovsky in assuming that applicatives project their own phrase, there is evidence that PIPs may be incorporated into the verb in at least some cases. In many cases of PIPCs, there is no overt expression of the possessor. Bresnan \& Mchombo (1987) argue for Chichewa that in cases in which there is no overt realization of an argument, the marking of this argument on the verb has the status of an incorporated pronoun rather than agreement. This kind of argument could be applied to PIPCs in cases in which there is no overt realization of the possessor. For example, the sentence in (41) comes from a picture description task in which the participant describes a picture of a monkey dropping a girl's bag that it has previously stolen from her. There is no overt expression of the possessor (or the subject) in this sentence:

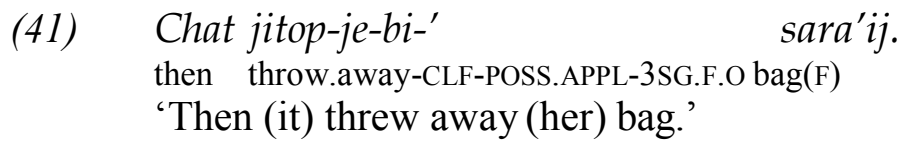

In this sentence, the suffix -' indicates a third person singular feminine object. Following Bresnan and Mchombo's approach, it could be argued that this suffix functions as an incorporated pronoun in this example, as there is no other referential element which corresponds to the possessor. In this way, Shklovsky's analysis of the agreement pattern in Tseltal as a kind of incorporation of the possessor may be applicable in at least some cases of PIPCs in Chimane. This idea will be developed further in Section 7. 
This is the accepted version of an article published by John Benjamins in Studies in Language Vol. 41 (3), 660-716. Published online 25 October 2017. Available from: https://doi.org/10.1075/sl.41.3.05rit Accepted version downloaded from SOAS Research Online: https://eprints.soas.ac.uk/25082/

\subsection{Mediated locality}

Another potential analysis of PIPCs for which there may be some evidence is the idea that the PIP has a representation or 'proxy' in the clause which stands in for it and functions as the object, and this is what enables the possessor to control object agreement. Again this idea has not been developed for PIPCs but appears in some analyses of LDA constructions. Polinsky (2003) and Le Sourd (2014) both argue that LDA between a verb and an argument in a subordinate clause is enabled by a proxy which doubles the argument of the subordinate clause in the matrix clause. Both Polinsky and Le Sourd show evidence for a free referential expression, either pronominal or nominal, which functions as an argument of a main clause and either binds an argument in a subordinate clause or 'raises' out of the subordinate clause (the term 'raising' is used descriptively, no movement is assumed in either Polinsky's or Le Sourd's analysis).

Polinksy cites several examples from Algonquian languages which seem to provide evidence of this proxy. For example, in Blackfoot, it is possible for the verb in the matrix clause $^{20}$ to agree with an argument in an embedded clause. Consider the examples in (42). In (42a), the verb in the matrix clause does not exhibit object agreement. This is the default construction. In (42b), the verb in the matrix clause exhibits objectagreement with the subject of the verb in the embedded clause noxkówa 'myson'.

$$
\begin{aligned}
& \text { a. nit-wikixtaa [n-oxko-wa m-áxk-a'po'takizsi] } \\
& \text { 1.SUBJ-want.INTR 1-son-3 3.SUBJ-might-work } \\
& \text { 'I want my son to work.' } \\
& \text { b. nit-wikixtatwaa-wa } \text { [n-oxko-wa }_{i} \text { m-áxk-a'po'takizsi] } \\
& \text { 1.SUBJ-want.TR-3.OBJ 1-son-3 3.SUBJ-might-work } \\
& \text { 'I want my son to work.' } \\
& \text { c. pro-1SG want pro-3 } \mathrm{SG}_{\mathrm{i}} \text { [my son-3 } \mathrm{SG}_{\mathrm{i}} \text { work] }
\end{aligned}
$$

(Polinsky 2003: 285)

Polinsky proposes that the agreement relation in (42b) between the verb in the matrix clause and the argument in the subordinate clause is 'mediated' by a proxy which stands

\footnotetext{
${ }^{20}$ Polinsky uses the term 'embedding clause' to refer to the clause which contains the agreement target, i.e. the verb of the matrix clause.
} 
This is the accepted version of an article published by John Benjamins in Studies in Language Vol. 41 (3), 660-716. Published online 25 October 2017. Available from: https://doi.org/10.1075/sl.41.3.05rit Accepted version downloaded from SOAS Research Online: https://eprints.soas.ac.uk/25082/

in for the argument of the embedded clause in the matrix clause. She schematizes this analysis as in (42c), where the proxy is represented by the 'pro-3SG' element, and the coreferential relationship between the proxy and the argument in the embedded clause is represented by the indices on both elements.

The PIPC in Chimane exhibits one particular feature which may support a this type of analysis involving a proxy which mediates the agreement relationship between the verb and the PIP. It is a common feature of PIPCs that the PIP is doubled by a bound possessor. (43) is an example of such a construction:

$$
\begin{aligned}
& \text { Mi naij-bi-te } \left.\text { [ococo Juan }_{j}-s i^{\prime}\right]_{i}=\mathbf{m u}{ }_{j} . \\
& \text { you see-POSS.APPL-3sG.M.o frog(F) } \quad \operatorname{Juan(M)-F\quad =him~} \\
& \text { 'You saw Juan's frog.' }
\end{aligned}
$$

[elicited]

It is possible that the doubling possessor in (43) is an overt expression of a proxy of the internal possessor in the clause. If this is the case, and it is this element which functions as the object of the verb, then it is possible to predict that this element can only occur in PIPCs and not in the corresponding IPC. In fact, this prediction appears to be borne out; the bound pronominal cannot easily occur in the default IPC. Its insertion in the IPC equivalent of (43) is considered strange or ungrammatical by my consultants:

$$
\begin{aligned}
& \text { (44) Mi naij-tye-'i }{ }^{\prime} \quad\left[\text { ococo Juan }{ }_{j}-\mathrm{si}^{\prime}\right]_{i}\left(?^{*}=m u^{\prime}\right) . \\
& \text { you see-CLF-3sG.F.o frog(F) Juan(M)-F }=\text { him } \\
& \text { ('You saw Juan's frog.') }
\end{aligned}
$$

This seems to indicate that the doubling possessor might be an external clause-level proxy of the internal possessor in the PIPC. The doubling possessor cannot easily occur in the IPC because it has no argument slot to fill in the clause, but it can in the PIPC because there is such an argument slot in that construction. In order to test this hypothesis, the properties of the doubling possessor in the PIPC require furtherconsideration.

Let us return to Polinsky's definition of proxies: “(i) the proxy ... is in the local domain of the agreeing verb, and (ii) the proxy is a free referential expression, not a pronominal 
This is the accepted version of an article published by John Benjamins in Studies in Language Vol. 41 (3), 660-716. Published online 25 October 2017. Available from: https://doi.org/10.1075/sl.41.3.05rit Accepted version downloaded from SOAS Research Online: https://eprints.soas.ac.uk/25082/

copy of the embedded representation" (2003: 284). With respect to the first part of this definition, in the case of LDA, the local domain is the matrix clause, while with PIPCs, it is the clause containing the possessive phrase. It is not entirely clear whether the doubling pronoun is in the local domain of the verb. (45) shows that the bound possessor can occur in a position separate from the rest of the possessive phrase, and this might be taken as evidence that it is external to it and functions as a clause-level element:

In (45), the bound possessor is separated from the possessive phrase by a clause-level adverb. However, as has already been discussed, discontinuity of constituents of the possessive phrase (and NPs generally) cannot necessarily be taken as evidence that they do not function as dependents of the phrasal head in a non-configurational language like Chimane. But the clitic does have some properties which seem to indicate that it does not have the same status as a discontinuous dependent of the possessive phrase. For example, while the clitic can potentially occur in other positions within the clause, e.g. it is possible for it to attach to the verb or any of the constituents of the possessive phrase (see Section 4.1), there is a distinct preference for it to attach to the final element of the clause, as in (45) where it attaches to the clause-final adverb. This preference is not shared by other discontinuous phrasal constituents, which usually precede and follow the verb and particles, as in (46) and (47) where the possessors and possessed nouns occur on either side of the verbs:
(46) Yu-ty na are'-yi pa'tyi'. my-M FOC hurt-CLF.GNL.M.S fingernail(M) 'My fingernails hurt.'

(47) Chime'dyeca sh i’-si' ca tu-qui-j bätäj. also HRSY tapir(M)-F HRSY bring-POSS.REFL-M.S hump(F) 'Again he brought them tapir's hump.' 
This is the accepted version of an article published by John Benjamins in Studies in Language Vol. 41 (3), 660-716. Published online 25 October 2017. Available from: https://doi.org/10.1075/sl.41.3.05rit Accepted version downloaded from SOAS Research Online: https://eprints.soas.ac.uk/25082/

This different distribution seems to indicate that the doubling possessor has a different status from discontinuous dependents of the possessive phrase, i.e. that it may bear a clause-level argument function, rather than being internal to the possessive phrase. The implications of this are discussed further in Section 7.

The second part of Polinsky's definition also initially seems to go against the analysis of the doubling possessor as a clause-level proxy. She explicitly states that the proxy must be a free referential expression and not a pronominal copy of the internal representation of the argument. The bound possessor seems to fail on this test, as it does appear to be merely a pronominal copy of the internal possessor.

Another type of evidence which seems to go against an analysis of the doubling possessor as a clause-level proxy is its distribution in other types of IPCs. In reflexive IPCs, i.e. constructions in which the possessed noun controls object agreement and the possessor is anaphorically bound by the subject, the occurrence of the bound possessor is preferred and is possibly required. My consultants questioned whether the construction in (48) was acceptable without the doubling possessor:

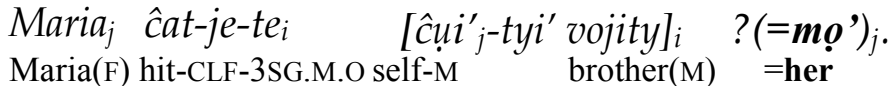

$$
\begin{aligned}
& \text { 'Maria hit her own brother.' }
\end{aligned}
$$

In (48), the possessed noun controls predicate-argument agreement and the subject binds the reflexive possessor chi $i$ 'tyi' 'own'. In this type of construction, the occurrence of the bound possessor is preferred over its omission. Recall that the bound possessor cannot easily occur in disjoint IPCs, as demonstrated by (44). This was taken as evidence that the doubling pronoun in the PIPC might function as a clause-level proxy of the internal possessor; the fact that it cannot occur in the disjoint IPC seems to indicate that there is no argument slot for it to fill. However, (48) is also a type of IPC, and is therefore also presumed to have no argument slot for an external proxy, because predicate-argument agreement indicates that the possessive phrase functions as the object. And yet here the occurrence of the doubling possessor is preferred. If there is no argument slot for a clause- 
This is the accepted version of an article published by John Benjamins in Studies in Language Vol. 41 (3), 660-716. Published online 25 October 2017. Available from: https://doi.org/10.1075/sl.41.3.05rit Accepted version downloaded from SOAS Research Online: https://eprints.soas.ac.uk/25082/

level proxy of the internal possessor in the reflexive IPC, then the doubling possessor must have some other status there, possibly as a kind of topic marker. And if it is the case that the doubling possessor has the status of a topic marker and not an argument in the reflexive PIPC, it could be argued that this is also the most appropriate analysis for the doubling possessor in the PIPC. However, there are several aspects of the PIPC which seem to support an analysis of the doubling possessor as a clause-level proxy of the internal possessor, despite the problems which have been set outhere.

The main argument in favour of a mediated locality-type analysis of the Chimane PIPC is the fact that agreement between the possessor and the verb is restricted to only occurring with objects. This is not the case in other languages which exhibit agreement between verbs and internal possessors. In Tabassaran (Nakh-Daghestanian), for example, possessors internal to any argument, and even possessors internal to non-arguments, can optionally control agreement on the verb:

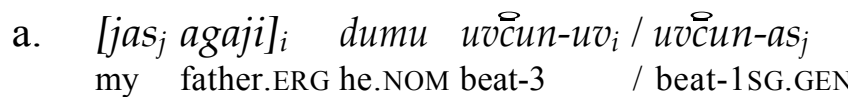
'My father has beaten him.'

b. $\quad$ duRu $\left[j a s_{j} a g a j i-s\right]_{i} \quad k^{\prime} a \check{z} \quad i k^{\prime} v-u v_{i} / i k^{\prime} n-a s_{j}$ he.ERG my father-DAT letter.NOM write-3 / write-1SG.GEN 'He wrote a letter to my father.'

c. baj $\left[j a s_{j} c^{\circ h} u k a-q^{h}\right]_{i} \quad h i t^{\prime} i k^{\prime} n-u v_{i} / h_{i t} i k^{\prime} n-a s_{j}$ boy my shed-POSTESS hide-3 / hide-1SG.GEN 'The boy hid behind my shed.'

d. duq'ari $\left[j a s_{j} j a k^{\prime} u-x i\right]_{i}$ hit'urd-uv $_{i} /$ hit'urd-as $_{j}$ they.ERG my axe-COM cut-3 / cut-1SG.GEN 'They are cutting (wood) with my axe.'

(Kibrik \& Seleznev 1980: 23-24) In all the examples in (49), agreement with the first person singular internal possessor is indicated by the first person singular genitive agreement affix -as. This agreement suffix is controlled by the possessor of the ergative subject in (49a), by the possessor of the dative recipient in (49b), by the possessor of the postessive NP in (49c), and by the possessor of the comitative NP in (49d). This is not possible in Chimane. For example, it is impossible 
This is the accepted version of an article published by John Benjamins in Studies in Language Vol. 41

(3), 660-716. Published online 25 October 2017. Available from: https://doi.org/10.1075/sl.41.3.05rit Accepted version downloaded from SOAS Research Online: https://eprints.soas.ac.uk/25082/

for a possessor internal to a subject NP to control predicate-argument agreement: ${ }^{21}$

$$
\begin{aligned}
& \text { a. }{ }^{*} M u^{\prime} \text { vojity }=y u \text { naij-bi-ye mi. } \\
& \text { the.M brother(M)=my see-POSS.APPL-1SG }>2 \text { SG you }
\end{aligned}
$$

b. ${ }^{*} M u^{\prime}$ vojity $=y u$ naij-tye-ye mi.
the.M brother(M)=my see-CLF-1SG $>2 \mathrm{SG}$ you

('My brother saw you.')

[elicited]

Agreement between the verb and a possessor internal to a subject NP is ungrammatical, whether the $-b i$ suffix is present, as in (50a), or not, as in (50b). This is also the case for all other argument and non-argument functions apart from objects. Another feature of agreement systems like that in Tabassaran is that the internal possessor can control agreement on the verb with no requirement for additional morphology. Again this is impossible in Chimane. The agreement pattern can only occur in the presence of the $-b i$ suffix:

In (51), the verb agrees with the possessor but the -bi suffix does not occur. This kind of construction is strictly ungrammatical.

Unlike languages like Tabassaran, Chimane exhibits a restricted paradigm of agreement between verbs and internal possessors, and these restrictions do seem to be syntactic in nature. As discussed in Section 5.3, Chimane PIPCs are akin to applicative constructions in that a non-argument (either the possessor or an oblique adjunct) in the default counterpart of the construction (the IPC or a monotransitive construction) appears to function as the object in the applicative construction. If the PIPC is akin to applicative constructions in these respects, then it also seems plausible to assume that the doubling possessor does represent some kind of clause-level proxy of the internal possessor which

\footnotetext{
${ }^{21}$ Possessors of subjects of passive applicative verbs can control agreement. I return to this point in Section 7.
} 
This is the accepted version of an article published by John Benjamins in Studies in Language Vol. 41

(3), 660-716. Published online 25 October 2017. Available from: https://doi.org/10.1075/sl.41.3.05rit Accepted version downloaded from SOAS Research Online: https://eprints.soas.ac.uk/25082/

functions similarly to an applied object in an applicative construction.

Further evidence that the PIPC may be similar to applicative constructions comes from its use with ditransitive verbs. Recall from Section 4.3 that the non-patient-like argument (i.e. the recipient or beneficiary etc.) invariably controls object agreement in double object constructions. In cases of ditransitive verbs featuring the - $b i$ suffix, this argument appears to correspond to the possessor. The following example comes from adescription of a picture of a girl giving a monkey its baby back after taking it away:

$$
\begin{aligned}
& J i{ }^{\prime}-c a \tilde{n}-e-b i-b a j-t e_{j} q u i a v a^{\prime}{ }_{i .} \\
& \text { CAUS-return-CLF-POSS.APPL-again-3SG.M.o so baby(F) } \\
& \text { 'So she [the girl] gives it [the monkey] back its baby.' }
\end{aligned}
$$

[tapact001.028]

In (52), the ditransitive verb exhibits the -bi suffix and the null masculine possessor controls object agreement. In all the examples of PIPCs discussed so far, PIPs control object agreement despite being internal to the single patient-like argument of a monotransitive verb. In (52), meanwhile, the possessor appears to correspond to the recipient-like argument of the ditransitive verb. This suggests that the possessor is an object of this verb as well as functioning as the possessor of the possessive patient-like argument, and that the possessor and possessive phrase may be associated with different object functions. In this scenario, the possessor functions as the primary object, as here it controls agreement and bears the recipient-like role, and the possessive phrase bears the secondary object function, as it does not control agreement and has a patient-like role. This configuration with ditransitives may indicate that in fact all verbs in PIPCs subcategorize for both a primary and secondary object function, with the possessor bearing the primary object function and the possessed noun the secondary object function. This also helps to explain two aspects of the construction. First the preference for the doubling pronoun in PIPCs versus its ungrammaticality in (non-reflexive) IPCs; if the external representation of the possessor is functioning as the agreement controlling primary object, then the doubling possessor is an overt expression of this clause-level argument. Second the obligatory occurrence of the -bi suffix even with verbs which are clearly not semantically ditransitive; despite 
This is the accepted version of an article published by John Benjamins in Studies in Language Vol. 41 (3), 660-716. Published online 25 October 2017. Available from: https://doi.org/10.1075/sl.41.3.05rit Accepted version downloaded from SOAS Research Online: https://eprints.soas.ac.uk/25082/

the fact that the possessor does not always bear a distinct semantic role in such cases, the suffix nevertheless alters the valency of the verb such that the clause-level representation of the possessor functions as the primary object and the possessive phrase headed by the possessed noun function as the secondary object.

\section{Proposed analysis}

To summarize the conclusions drawn about the syntactic structure of the PIPC so far: PIPs do not appear to be external to the possessive phrase, nor do they have any morphosyntactic properties which suggest that they function as the head of the possessive phrase or that they occupy a more prominent position within the phrase. However, there is some evidence from the optional occurrence of the doubling possessor in the construction, from the obligatory occurrence of the -bi suffix which seems to have some properties of an applicative, and from the semantic role of the PIP in ditransitive PIPCs that the possessor has an external representation which functions as the applied object of the applicative verb. This is the analysis which will be assumed for the PIPC in this study.

The first point to note about this analysis is that the external representation of the PIP is not necessarily overtly expressed. Many of the examples of PIPCs presented in this study do not feature the doubling possessor which appears to be an overt expression of the external representation. Therefore, as discussed in Section 6.3, I will follow Bresnan \& Mchombo (1987) in assuming that the agreement morphology on the verb functions as an incorporated pronoun and bears the grammatical function instead of the doubling possessor in such cases. A second point is the correspondence between PIPs and their external representations. As discussed in Section 6.4, when overt, the doubling possessor must match the features of the PIP one-to-one. Therefore, this element will be analysed as being anaphorically controlled by the PIP.

Taking all these features of the analysis of the PIPC together, it is possible to provide a representation of the construction following the representation of LDA constructionsin 
This is the accepted version of an article published by John Benjamins in Studies in Language Vol. 41 (3), 660-716. Published online 25 October 2017. Available from: https://doi.org/10.1075/sl.41.3.05rit Accepted version downloaded from SOAS Research Online: https://eprints.soas.ac.uk/25082/

Algonquian languages proposed by Polinsky (2003). She schematizes mediated locality in LDA constructions as in (53), where $\mathrm{Agr}_{\mathrm{i}}$ indicates predicate-argument agreement controlled by the proxy NP, which is in turn coindexed with the NP in the embedded clause:

$$
\left[\text { IP Subject } V+\operatorname{Agr}_{i} \mathrm{NP}_{\mathrm{i}}\left[\mathrm{CP} / \mathrm{IP} \ldots \mathrm{NP}_{\mathrm{i}} \ldots\right]\right]
$$

The analysis of Chimane presented here will follow this schema with some additions. Since the analysis relies on alternative mappings between the various clausal constituents and grammatical functions, the correspondences between these two are also indicated in the representation. As well as the familiar subject, object and oblique functions, the elements bearing the possessor and possessed noun functions are also represented as PSR and PSE respectively, though it is important to note that these functions are not subcategorized by the verb. Representations of the IPC and EPC are shown first in (54) and (55), as they both provide useful points for comparison with the PIPC.

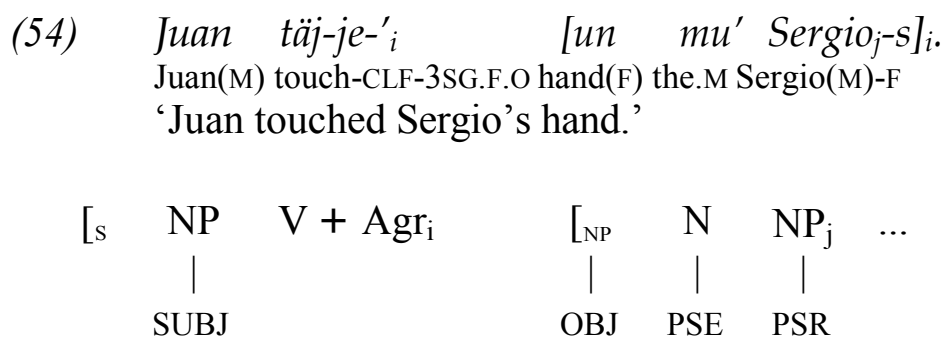

(54) is a representation of the structure of the default IPC. As this representation makes explicit, I assume that in this construction, the possessive phrase headed by the possessed noun bears the object function and the internal possessor has no external representation in the clause. This explains why the doubling possessor cannot occur in the IPC. Apart from the more complex internal structure of the possessive phrase, the default IPC has exactly the same structure as basic transitive clauses in Chimane.

The EPC also has the basic structure of a default transitive clause, in this case with the possessor functioning as the object and the possessed noun as an oblique adjunct. Here the relationship of possession is not expressed by any syntactic means. 
This is the accepted version of an article published by John Benjamins in Studies in Language Vol. 41 (3), 660-716. Published online 25 October 2017. Available from: https://doi.org/10.1075/sl.41.3.05rit Accepted version downloaded from SOAS Research Online: https://eprints.soas.ac.uk/25082/

$\left[\begin{array}{ccc}\mathrm{s} & \mathrm{NP} & \mathrm{V}+\operatorname{Agr}_{\mathrm{j}}\end{array}\right.$

SUBJ

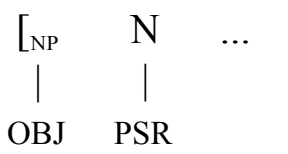

The IPC and EPC can be analysed simply as transitive constructions in which either the possessive phrase headed by the possessed noun or the external possessor bears the function of the single object of a monotransitive verb.

Turning now to the PIPC, the first type which will be considered is that featuring the doubling possessor. As argued above, the doubling possessor is analysed in this study as an overt realization of a clause-level representation of the PIP which functions as the primary object of the verb. The possessive phrase headed by the possessed noun is analysed as bearing a secondary object function, but otherwise has the same internal structure as that in the default IPC. The anaphoric control of the doubling possessor by the PIP is shown by the indices.

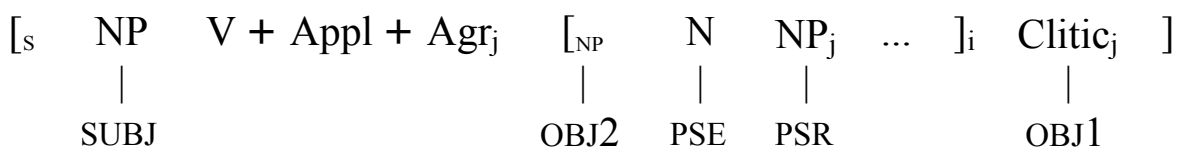

As shown in Section 5, free PIPs can occur discontinuously from the rest of the possessive phrase. However, the fact that the PIP can be separated from the rest of the possessive phrase does not imply that it is external to it. Following Austin \& Bresnan (1996) inter alia, I will assume that constituents of discontinuous NPs are dominated by identical ${ }^{22}$ NPs. The structure of a phrase with a discontinuous PIP can therefore be represented as in (57), where the identical NPs are coindexed and bear the same grammatical function:

\footnotetext{
${ }^{22}$ The term 'identical' is used here to indicate that although the constituents of an NP are discontinuous, they are both dominated by the same NP.
} 
This is the accepted version of an article published by John Benjamins in Studies in Language Vol. 41 (3), 660-716. Published online 25 October 2017. Available from: https://doi.org/10.1075/sl.41.3.05rit Accepted version downloaded from SOAS Research Online: https://eprints.soas.ac.uk/25082/

$$
\begin{aligned}
& Y u\left[\text { miquity }_{j}-\text { si' }_{i}\right]_{i} \text { naij-bi-te } \\
& \text { I boy(M)-F } \\
& \text { see-POSS.APPL-3sG.M.o the.F } \\
& \text { 'I saw the boy's frog.' }
\end{aligned}
$$

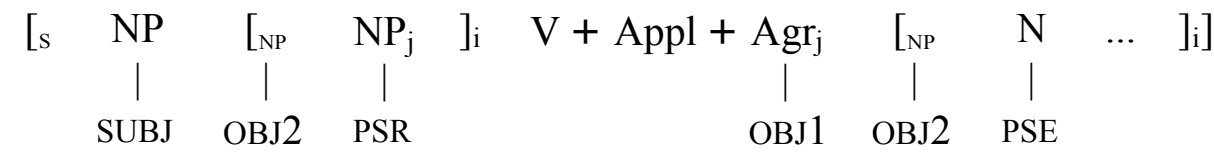

Here the NP headed by the PIP is dominated by another NP which is identical to that dominating the possessed noun. As this representation makes explicit, it is not assumed here that the discontinuous PIP bears the object function, unlike the doubling possessor in (56). Instead, as discussed in Section 6.3, it is assumed that the agreement marker on the verb functions as an incorporated pronoun which bears the object function in cases like this where there is no overt doubling possessor.

One other potential issue with the analysis is the fact that PIPs can also be realized as bound pronouns (see Section 4.1). This element cannot bear both the object and possessor functions as a referential expression cannot bear more than one grammatical function in a clause. I assume in such cases that the bound PIP does not have the same status as the doubling possessor. Instead, it bears the possessor function and the object function is borne by the incorporated pronoun on the verb, just as it is in(57).

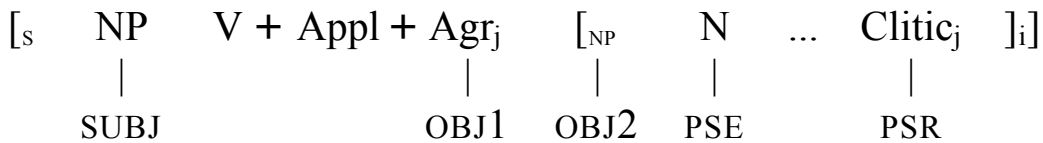

It may also be the case that the bound PIP bears the object function and the possessor function is incorporated into the possessed noun (as in example (60) below). However, given that the bound possessor can also occur in the IPC, in which it is assumed that the possessive phrase bears the object function, this analysis seems less plausible. One consultant also doubted the grammaticality of a sentence such as (59), in which the bound PIP 
This is the accepted version of an article published by John Benjamins in Studies in Language Vol. 41 (3), 660-716. Published online 25 October 2017. Available from: https://doi.org/10.1075/sl.41.3.05rit Accepted version downloaded from SOAS Research Online: https://eprints.soas.ac.uk/25082/

attaches to a clause-level adverb. This seems to indicate that the bound PIP is a phraselevel clitic, rather than a clause-level clitic like the doubling possessor. It is represented as such in (58).

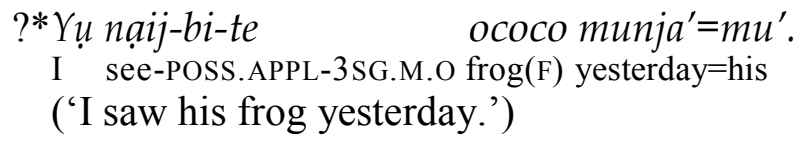

[elicited]

Clauses with no expression of the PIP as a nominal or clitic also require further explanation. Analogously to the way that the incorporated pronoun bears the object function when there is no expression of the PIP in the clause, I will assume that the possessor function is incorporated into the possessed noun when there is no expression of the PIP in the possessive phrase. The structure of a clause with no overt expression of the PIP can be represented as follows. The clause-level adverb chat is not represented and it is assumed that the agreement marker on the verb is a portmanteau which also bears the subject function as well as the object function. The possessed noun is a kind of 'portmanteau' which bears both the possessed noun and the internal possessor function (represented by PSE + PSR).

$$
\begin{aligned}
& \text { Chat jitop-je-bi-' }{ }_{j} \quad \text { sara' }^{\prime} i_{i} \text {. } \\
& \text { then throw.away-CLF-POSS.APPL-3SG.F.o bag(F) } \\
& \text { 'Then (it) threw away (her) bag.' }
\end{aligned}
$$

[tarovs001.025]

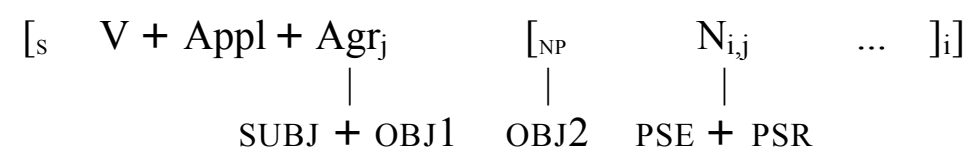

One other type of PIPC which requires further explanation is the passive variant. The subject of the verb in a passive PIPC corresponds to the object of the non-passive variant. Following the analysis proposed here, this element would be the external representation of the PIP which bears the object function in the non-passive variant. In this case, two valency changing processes occur. The applicative increases the valency by adding the PIP as the primary object and demoting the possessive phrase to the secondary object 
This is the accepted version of an article published by John Benjamins in Studies in Language Vol. 41 (3), 660-716. Published online 25 October 2017. Available from: https://doi.org/10.1075/sl.41.3.05rit Accepted version downloaded from SOAS Research Online: https://eprints.soas.ac.uk/25082/

function. Then the passive decreases the valency by promoting the primary object to the subject. Therefore as well as subcategorizing for this subject argument, the verb in such construction retains its secondary object function, and this function continues to be borne by the possessive phrase:

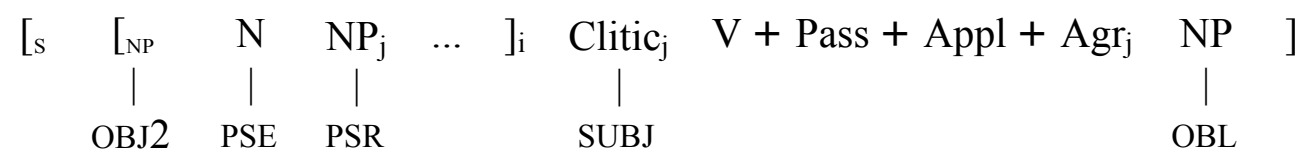

(61) shows that the doubling possessor bears the subject function of the passive verb, while the possessive phrase bears the secondary object function. Meanwhile the former subject of the non-passive verb is demoted to the status of an oblique adjunct (agents in passive constructions are not marked by any oblique marking in Chimane).

To summarise, an analysis of PIPCs in Chimane has been provided in which it is argued that PIPs have an clause-level representation which can be optionally realized by the doubling possessor. When the external representation is not realized by the doubling possessor, I assume that the agreement marking on the verb functions as an incorporated pronoun and bears the object function in place of the clause-level representation of the PIP. The latter is assigned the primary object function, while the possessive phrase headed by the possessed noun bears the secondary object function. Following this analysis, the structure of the various types of PIPC discussed in this study can be accounted for in a unified way.

\section{Summary and further questions}

This study has shown that agreement between the verb and the internal possessor in Chimane can be accounted for by assuming that the agreement is mediated by a clause-level 
This is the accepted version of an article published by John Benjamins in Studies in Language Vol. 41

(3), 660-716. Published online 25 October 2017. Available from: https://doi.org/10.1075/sl.41.3.05rit Accepted version downloaded from SOAS Research Online: https://eprints.soas.ac.uk/25082/

element which bears the object function in the clause and is anaphorically controlled by the internal possessor. This mediated locality-type analysis helps to explain how PIPs can control agreement on a target which is not in their local domain. If this analysis is correct, then this explains why the PIPC seems to share features in common with both IPCs and EPCs; while it seems to be superficially similar to the IPC in terms of the marking of possessors, it is in fact much closer to EPCs, in particular those in which the EP is promoted to object status via an applicativization-like process, as has been argued for example in Oluta Popoluca (Mixean) by Zavala (1999). The only complication in Chimane is that rather than the PIP itself being promoted to primary object status, an element which is anaphorically bound by the PIP is promoted to this function instead. The use of this process in ditransitive constructions is revealing in this regard, since in those cases, the referent of the possessor is bearing two distinct but not mutually exclusive semantic roles: one as the non-patient-like argument (the recipient or beneficiary etc.), and one as the possessor of the patient-like argument. In fact, it may well be the case that the more semantically bleached uses of the PIPC, for example with non-affecting predicates like 'see' and stative predicates like 'know', in which there is no clear non-patient-like semantic role, developed by analogy from this more semantically motivated use in ditransitive constructions.

Unfortunately there are no historical texts for Chimane, therefore it is difficult to reconstruct earlier stages of the language. However, it seems plausible to assume that the more widespread contemporary use of the PIPC did develop in this way. But this begs the question of why the use of the PIPC was extended to verbs in which there is no nonpatient-like semantic role for the PIP to map to. In the introduction I briefly alluded to the fact that PIPCs alternate with IPCs in discourse, and that the alternation is motivated by the semantic and/or information structural role which is borne by the possessor. In the case of a ditransitive construction in which the possessor bears a recipient or beneficiary role, it is clear to see why the PIPC is preferred over the IPC, as it signals that the PIP bears a semantic role (and an argument function) which is different from the possessive 
This is the accepted version of an article published by John Benjamins in Studies in Language Vol. 41 (3), 660-716. Published online 25 October 2017. Available from: https://doi.org/10.1075/sl.41.3.05rit Accepted version downloaded from SOAS Research Online: https://eprints.soas.ac.uk/25082/

phrase headed by the possessed noun. However, in cases in which the possessor does not have a semantic role different from the possessive phrase, then there must be a different motivation for choosing between the PIPC and the IPC. It is beyond the scope of this study to go into detail on the discourse function of the PIPC, but initial evidence seems to suggest that the PIPC is preferred when the possessor bears a topical information structure role in the wider discourse. More specifically, since only PIPs in object NPs can control agreement on the verb, and subjects usually (but not always) bear the primary topic role in discourse, it seems to be the case that the PIPC is preferred when the possessor bears the secondary topic role, defined as "an entity such that the utterance is construed to be ABOUT the relationship between it and the primary topic" (Nikolaeva 2001: 26). A detailed investigation of the discourse function of the PIPC is therefore required to provide a more complete picture of this complex phenomenon. 
This is the accepted version of an article published by John Benjamins in Studies in Language Vol. 41 (3), 660-716. Published online 25 October 2017. Available from: https://doi.org/10.1075/sl.41.3.05rit Accepted version downloaded from SOAS Research Online: https://eprints.soas.ac.uk/25082/

\section{${ }_{1503}$ Acknowledgements}

This research was principally funded by a grant from the Arts and Humanities Research Council (AHRC) (Grant no. AH/J500410/1), with additional funding for fieldwork from the Endangered Languages Documentation Programme (ELDP) (Grant no. SG0272) and from SOAS, University ofLondon.

Many thanks to Irina Nikolaeva, Oliver Bond and the reviewers of Studies in Language for providing detailed comments on earlier drafts of this paper. Any remaining errors are my own.

Thanks also to the Chimane community, especially Benjamin, Santa, and Cupertino Caity, Berthi Cayuba, Leonilda Plata, Dino Nate, and Manuel Roca, Margarita Lero, Felipe Mayer, Tomás Tayo, Rosa Mendoza, and Maria Lurdes. The Gran Consejo Tsimane’ and its former president Candido Nery are also acknowledged for allowing me to access the communities. A special thanks to Tomás Huanca for logistical support in Bolivia. 
This is the accepted version of an article published by John Benjamins in Studies in Language Vol. 41 (3), $660-$

716. Published online 25 October 2017. Available from: https://doi.org/10.1075/sl.41.3.05rit

Accepted version downloaded from SOAS Research Online: https://eprints.soas.ac.uk/25082/

\section{${ }_{1516}$ Abbreviations}

\begin{tabular}{|c|c|c|c|}
\hline . & fused meaning & INTR & intransitive \\
\hline- & affix boundary & IPC & internal possessor construction \\
\hline$=$ & clitic boundary & IRR & irrealis \\
\hline$(x)$ & inherent feature & LDA & long distance agreement \\
\hline$>$ & direction of action & LOC & locative \\
\hline 1 & first person & M & masculine \\
\hline 2 & second person & $\mathrm{N}$ & neuter \\
\hline 3 & third person & NEG & negative \\
\hline ABS & absolutive & $\mathrm{NH}$ & non-honorific \\
\hline APPL & applicative & NOM & nominative \\
\hline BEN & benefactive & $\mathrm{O} / \mathrm{OBJ}$ & object \\
\hline CLF & classifier & OBL & oblique \\
\hline CAUS & causative & PASS & passive \\
\hline $\mathrm{COM}$ & comitative & PFV & perfective \\
\hline DAT & dative & PIP & prominent internal possessor \\
\hline DIM & diminutive & PIPC & prominent internal possessor construction \\
\hline EP & external possessor & PL & plural \\
\hline EPC & external possessor construction & POSS & possessive \\
\hline EPEN & epenthetic & POSTESS & postessive \\
\hline ERG & ergative & PROG & progressive \\
\hline EXCL & exclusive & PSE & possessed noun \\
\hline $\mathrm{F}$ & feminine & PSR & possessor \\
\hline FOC & focus & $\mathrm{Q}$ & question \\
\hline GEN & genitive & REFL & reflexive \\
\hline GNL & general meaning & S/SUBJ & subject \\
\hline $\mathrm{H}$ & honorific & SG & singular \\
\hline HRSY & hearsay & SUPE & superessive \\
\hline INCL & inclusive & TR & transitive \\
\hline INTERR & interrogative & & \\
\hline
\end{tabular}


This is the accepted version of an article published by John Benjamins in Studies in Language Vol. 41 (3), 660-716. Published online 25 October 2017. Available from: https://doi.org/10.1075/sl.41.3.05rit Accepted version downloaded from SOAS Research Online: https://eprints.soas.ac.uk/25082/

\section{References}

Adelaar, Willem F. H. \& Pieter Muysken. 2004. The Languages of the Andes. Cambridge: Cambridge University Press.

Austin, Peter K. \& Joan Bresnan. 1996. Non-Configurationality in Australian Aboriginal Languages. Natural Language and Linguistic Theory 14. 215-268.

Bibolotti, Benigno. 1917. Moseteno Vocabulary and Treaties from an Unpublished Manuscript in Possession of Northwestern University Library, with an Introduction by Rudolph Schuller. Evaston and Chicago: Northwestern University.

Bickel, Balthasar, Walter Bisang \& Yogendra P. Yadava. 1999. Face vs. Empathy: The Social Foundation of Maithili Verb Agreement. Linguistics 37(3). 481-518.

Bickel, Balthasar, Bernard Comrie \& Martin Haspelmath. 2004. The Leipzig Glossing Rules. Conventions for Interlinear Morpheme by Morpheme Glosses. Leipzig: MaxPlanck Institute for Evolutionary Anthropology.

Bobaljik, Jonathan D. \& Susi Wurmbrand. 2002. Notes on Agreement in Itelmen. Linguistic Discovery 1(1).

Bresnan, Joan. 1982. The Mental Representation of Grammatical Relations. Cambridge, MA: MIT Press.

Bresnan, Joan \& Sam A. Mchombo. 1987. Topic, Pronoun, and Agreement in Chichewa. Language 63(4). 741-782.

Campbell, Lyle. 1997. American Indian Languages: The Historical Linguistics of Native America. New York/Oxford: Oxford University Press.

Chafe, Wallace L. 1980. The Pear Stories: Cognitive, Cultural, and Linguistic Aspects of Narrative Production. Norwood, New Jersey: Ablex. 
This is the accepted version of an article published by John Benjamins in Studies in Language Vol. 41 (3), 660-716. Published online 25 October 2017. Available from: https://doi.org/10.1075/sl.41.3.05rit Accepted version downloaded from SOAS Research Online: https://eprints.soas.ac.uk/25082/

Comrie, Bernard. 2003. When Agreement Gets Trigger Happy. Transactions of the Philological Society 101(2). 313-337.

Crevels, Mily. 2009. Bolivia Amazónica. In Inge Sichra (ed.), Atlas Sociolingüistico de Pueblos Indigenas En América Latina, vol. 1, Quito, Ecuador: FUNPROEIBAndes/UNICEF.

Daillant, Isabelle. 2003. Sens dessus dessous: Organisation sociale et spatiale des Chimane d'Amazonie bolivienne. Nanterre: Société d'ethnologie.

Dalrymple, Mary \& Irina Nikolaeva. 2011. Objects and Information Structure. Cambridge: Cambridge University Press.

Davies, William D. 1984. Inalienable Possession and Choctaw Referential Coding. International Journal of American Linguistics 50(4). 384-402.

de Bolivar, Gregorio. 1906. Relación de La Entrada Del Padre Fray Gregorio de Bolivar En Compañia de Diego Ramirez de Carlos, Á Las Provincias de Indios Chunchos, En 1621. In Victor M. Maurtua (ed.), Juicio de Limites Entre El Perú Y Bolivia, vol. 8, 205-237. Barcelona.

Dhakal, Dubi Nanda. 2015. Darai Verb Agreement. Himalayan Linguistics 14(2). 1-38.

Dixon, Robert M. W. 2000. Categories of the Noun Phrase in Jarawara. Journal of Linguistics 36(3). 487-510.

Dixon, Robert M. W. \& Alexandra Y. Aikhenvald. 1999. Introduction. In Robert M. W. Dixon \& Alexandra Y. Aikhenvald (eds.), The Amazonian Languages, 1-21. Cambridge: Cambridge University Press.

Dryer, Matthew S. 1986. Primary Objects, Secondary Objects, and Antidative. Language 62(4). 808-845.

Eisenbeiss, Sonja, Bill McGregor \& Claudia Maria Schmidt. 1999. Story Book Stimulus for the Elicitation of External Possessor Constructions and Dative Constructions ('the 
This is the accepted version of an article published by John Benjamins in Studies in Language Vol. 41 (3), 660-716. Published online 25 October 2017. Available from: https://doi.org/10.1075/sl.41.3.05rit Accepted version downloaded from SOAS Research Online: https://eprints.soas.ac.uk/25082/

Circle of Dirt'). In David Wilkins (ed.), Manual for the 1999 Field Season, 140-144.

Nijmegen: Max Planck Institute for Psycholinguistics.

Filimonova, Elena. 2005. Introduction. In Clusivity: Typology and Case Studies of the Inclusive-Exclusive Distinction, ix-xii. Amsterdam; Philadelphia: John Benjamins.

Fraser, Norman M., Greville G. Corbett \& Scott McGlashan. 1992. Introduction. In Greville G. Corbett, Norman M. Fraser \& Scott McGlashan (eds.), Heads in Grammatical Theory, 1-10. Cambridge: Cambridge University Press.

Gill, Wayne. 1987. Me' ca Ji'caviti Muntyi' Benic an in [What Happened to the People in the Beni]. San Borja, Bolivia: Nueva Vida.

Gill, Wayne. 1993. Diccionario Tsimane'-castellano Y Castellano-Tsimane'. San Borja, Bolivia: New Tribes Mission.

Gill, Wayne. 1999a. Chimane-English Dictionary. San Borja, Bolivia: New Tribes Mission.

Gill, Wayne. 1999b. A Pedagogical Grammar of the Chimane (Tsimané) Language. San Borja, Bolivia: New Tribes Mission.

Golovko, Evgenij. 2009. Aleutskij Jazyk v Rossijskoj Federacii (Struktura, Funkcionirovanie, Kontaktnye Javlenija). [The Aleut Language in the Russian Federation: Structure, Functioning, Contact Phenomena.]. Saint Petersburg: Russian Academy of Sciences Doctoral thesis.

Greenberg, Joseph H. 1987. Language in the Americas. Stanford, CA: Stanford University Press.

Grinevald, Colette. 1996. Propuesta de Alfabeto de La Lengua Mosetén [Proposal for the Alphabet of the Mosetén Language]. In Taller de Alfabetos de Las Lenguas Del Oriente Boliviano, Tumichukua. [Alphabeticization Workshop for the Languages of Eastern Bolivia, Tumichukua], Bolivia. 
This is the accepted version of an article published by John Benjamins in Studies in Language Vol. 41 (3), 660-716. Published online 25 October 2017. Available from: https://doi.org/10.1075/sl.41.3.05rit Accepted version downloaded from SOAS Research Online: https://eprints.soas.ac.uk/25082/

Guillaume, Antoine. 2008. A Grammar of Cavineña. Berlin: Mouton de Gruyter.

Hale, Kenneth. 1983. Warlpiri and the Grammar of Non-Configurational Languages. Natural Language and Linguistic Theory 1. 5-47.

Hamilton, Michael D. to appear. Ditransitives and Possessor Raising in Mi'gmaq. In Papers of the Algonquian Conference 46, .

Himmelmann, Nikolaus. 1998. Documentary and Descriptive Linguistics. Linguistics 36. $161-195$.

Huanca, Tomás L. 2005. Tsimane' Oral Tradition, Landscape and Identity in Tropical Rainforest. La Paz: Campo Iris.

Instituto Nacional de Estadística. 2001. Bolivia Censo 2001. Tech. Rep.

Instituto Nacional de Estadistica. 2012. Bolivia Censo 2012. Tech. Rep.

Jara-Ettinger, Julian, Edward Gibson, Celeste Kidd \& Steve Piantadosi. 2015. Native Amazonian Children Forego Egalitarianism in Merit-Based Tasks When They Learn to Count. Developmental Science .

Jara-Ettinger, Julian, Steven T. Piantadosi, Elizabeth Spelke, Roger Levy \& Edward Gibson. in press. Mastery of the Logic of Natural Numbers Is Not the Result of Mastery of Counting: Evidence from Late Counters. Developmental Science .

Kashyap, Abhishek Kumar. 2012. The Pragmatic Principles of Agreement in Bajjika Verbs. Journal of Pragmatics 44. 1868-1887.

Kaufman, Terrence. 1990. Language History in South America: What We Know and How to Know More. In Doris L. Payne (ed.), Amazonian Linguistics, 13-74. Austin: University of Texas Press.

Kepping, Ksenia B. 1979. Elements of Ergativity and Nominativity in Tangut. In Frans Plank (ed.), Ergativity, 263-277. London: Academic Press. 
This is the accepted version of an article published by John Benjamins in Studies in Language Vol. 41 (3), 660-716. Published online 25 October 2017. Available from: https://doi.org/10.1075/sl.41.3.05rit Accepted version downloaded from SOAS Research Online: https://eprints.soas.ac.uk/25082/

Kibrik, Alexsandr E. \& A. Seleznev. 1980. Sintaksis I Morfologija Glagol'nogo Soglasovanija v Tabasaranskom Jazyke [The Syntax and Morphology of Verbal Agreement in Tabassaran]. In Vladimir Zvegincev (ed.), Tabasaranskie Etjudy. Materialy Dagestanskoj Ekspedicii 1979 G, 17-33. Moscow: MGU.

Kiyosawa, Kaoru. 2004. The Distribution of Possessive Applicatives in Interior Salish Languages. Papers for the 39th International Conference on Salish and Neighbouring Languages, University of British Columbia Working Papers in Linguistics 14. 241-252.

Le Sourd, Peter. 2014. Raising and Long Distance Agreement in MaliseetPassamaquoddy: A Unified Analysis. In Proceedings of the 21st International Conference on Head-Driven Phrase Structure Grammar, Buffalo, NY: University at Buffalo.

Lyons, Christopher. 1986. The Syntax of English Genitive Constructions. Journal of Linguistics 22(1). 123-143.

Majid, Asifa. 2012. A Guide to Stimulus-Based Elicitation for Semantic Categories. In Nicholas Thieberger (ed.), The Oxford Handbook of Linguistic Fieldwork, 54-71. New York/Oxford: Oxford University Press.

Mayer, Mercer. 1969. Frog, where Are You? New York: Dial.

McGill, Stuart. 2009. Gender and Person Agreement in Cicipu Discourse: School of Oriental and African Studies, University of London Doctoral thesis.

Meakins, Felicity \& Rachel Nordlinger. under review. Possessor Dissension in the Ngumpin-Yapa Languages of Northern Australia. .

Mel'čuk, Igor A. 2001. Communicative Organization in Natural Language: The Semantic-Communicative Structure of Sentences. Amsterdam; Philadelphia: John Benjamins.

Métraux, Alfred. 1942. The Native Tribes of Eastern Bolivia and Western Mato Grosso 
This is the accepted version of an article published by John Benjamins in Studies in Language Vol. 41 (3), 660-716. Published online 25 October 2017. Available from: https://doi.org/10.1075/sl.41.3.05rit Accepted version downloaded from SOAS Research Online: https://eprints.soas.ac.uk/25082/

Bulletin 134 of the Smithsonian Institution. Washington: Bureau of American Ethnology.

Neukom, Lucas. 2000. Argument Marking in Santali. Mon-Khmer Studies 30. 95-113.

Nikolaeva, Irina. 2001. Secondary Topic as a Relation in Information Structure. Linguistics 39(1). 1-49.

Nikolaeva, Irina. 2005. Agreement and Situation Construal. In M. M. Jocelyne Fernandez-Vest (ed.), The Uralic Languages Today. A Linguistic and Cognitive Approach, 533-546. Paris: Librairie Honoré Champion, Editeur.

Nikolaeva, Irina. 2014a. A Grammar of Tundra Nenets. Berlin, Boston: Mouton de Gruyter.

Nikolaeva, Irina. 2014b. Internal Prominent Possessors. Paper Presented at the 6th International Conference on the Syntax of the World's Languages, Pavia, 8-10 September 2014.

Payne, Doris L. \& Immanuel Barshi. 1999. External Possession: What, Where, How, and Why. In Doris L. Payne \& Immanuel Barshi (eds.), External Possession, 3-29. Amsterdam: John Benjamins.

Peterson, David A. 2007. Applicative Constructions. Oxford: Oxford University Press.

Piantadosi, Steven T., Julian Jara-Ettinger \& Edward Gibson. 2014. Children's Development of Number in an Indigenous Farming-Foraging Group. Developmental Science 17(4). 553-563.

Polinsky, Maria. 2003. Non-Canonical Agreement Is Canonical. Transactions of the Philological Society 101(2). 279-312.

Polinsky, Maria \& Eric Potsdam. 2001. Long-Distance Agreement and Topic in Tsez. Natural Language E Linguistic Theory 19. 583-646. 
This is the accepted version of an article published by John Benjamins in Studies in Language Vol. 41 (3), 660-716. Published online 25 October 2017. Available from: https://doi.org/10.1075/sl.41.3.05rit Accepted version downloaded from SOAS Research Online: https://eprints.soas.ac.uk/25082/

Sakel, Jeanette. 2002. Gender Agreement in Mosetén. In Mily Crevels, Simon van der Kerke, Sérgio Meira \& Hein van der Voort (eds.), Current Studies on South American Languages, 287-305. Leiden: CNWS.

Sakel, Jeanette. 2004. A Grammar of Mosetén. Berlin: Mouton de Gruyter.

Sakel, Jeanette. 2005. Development of an Inclusive/Exclusive Distinction: A Possible Loan Scenario in Mosetenan. In Elena Filimonova (ed.), Clusivity, Amsterdam: Benjamins.

Sakel, Jeanette. 2007. The Verbness Markers of Mosetén Complex Predicates. In Bernhard Wälchli \& Matti Miestamo (eds.), New Trends in Typology: Broadening the Horizons and Redefining the Foundations, 315-338. Berlin: Mouton de Gruyter.

Sakel, Jeanette. 2009. Mosetén Y Chimane. In Mily Crevels \& Pieter Muysken (eds.), Las Lenguas de Bolivia, 333-375. La Paz, Bolivia: Plurales Editores.

Sakel, Jeanette. 2011. Mosetén and Chimane Argument Coding: A Layered System. International Journal of American Linguistics 77(4). 537-557.

Shibatani, Masayoshi. 1994. An Integrational Approach to Possessor Raising, Ethical Datives, and Adversative Passives. In Proceedings of the Berkeley Linguistics Society, vol. 20, 461-486. Berkeley, CA: Berkeley Linguistics Society.

Shklovsky, Kirill. 2012. Tseltal Clause Structure. Cambridge, MA: Massachusetts Institute of Technology Doctoral thesis.

Stump, Gregory T. \& Ramawatar Yadav. 1988. Maithili Verb Agreement and the Control Agreement Principle. In Diane Brentari, Gary Larson \& Lynn MacLeod (eds.), Papers from the 24th Annual Regional Meeting of the Chicago Linguistic Society, Part Two: Parasession on Agreement in Grammatical Theory, 304-321. Chicago: Chicago Linguistic Society. 
This is the accepted version of an article published by John Benjamins in Studies in Language Vol. 41 (3), 660-716. Published online 25 October 2017. Available from: https://doi.org/10.1075/sl.41.3.05rit Accepted version downloaded from SOAS Research Online: https://eprints.soas.ac.uk/25082/

Suárez, Jorge A. 1969. Mosetén and Pano-Tacanan. Anthropological Linguistics 11(9). $255-266$.

Suárez, Jorge A. 1973. Macro-Pano-Tacanan. International Journal of American Linguistics 39(3). 137-154.

Swadesh, Morris. 1963. Acerca de Languages Aborigines de America Latina [On Aboriginal Languages of Latin America]. Current Anthropology 4. 317-318.

Van Gijn, Rik. 2006. A Grammar of Yurakaré. Nijmegen: Radboud University dissertation.

Van Staden, Miriam, Gunter Senft, Jürgen Bohnemeyer \& N. J. Enfield. 2001. Staged Events. In Stephen C. Levinson \& N. J. Enfield (eds.), Manual for the Field Season 2001, 115-125. Nijmegen: Max Planck Institute for Psycholinguistics.

Vázquez Álvarez, Juan Jesús. 2011. A Grammar of Chol, a Mayan Language. Austin, TX: The University of Texas at Austin Doctoral thesis.

Verma, Manindra K. 1991. Exploring the Parameters of Agreement: The Case of Magahi. Language Sciences, 13(2). 125-143.

Wilde, Christopher P. 2008. A Sketch of the Phonology and Grammar of Ra jbandit:TheUniversity ofHelsinkiDoctoral thesis.

Willson, Stephen R. 1996. Verb Agreement and Case Marking in Burushaski. Work Papers of the Summer Institute of Linguistics 40. 1-71.

Yadav, Ramawatar. 1996. A Reference Grammar of Maithili (Trends in Linguistic Documentation 11). Berlin: Mouton de Gruyter.

Zavala, Roberto. 1999. External Possessor in Oluta Popoluca (Mixean): Applicatives and Incorporation of Relational Terms. In Doris L. Payne \& Immanuel Barshi (eds.), External Possession, 339-372. Amsterdam; Philadelphia: John Benjamins. 
This is the accepted version of an article published by John Benjamins in Studies in Language Vol. 41 (3), 660-716. Published online 25 October 2017. Available from: https://doi.org/10.1075/sl.41.3.05rit Accepted version downloaded from SOAS Research Online: https://eprints.soas.ac.uk/25082/

1710 Zwicky, Arnold M. 1985. Heads. Journal of Linguistics 21. 1-29.

1711 Zwicky, Arnold M. \& Geoffrey K. Pullum. 1983. Cliticization vs. Inflection: English N't. $1712 \quad$ Language 59. 502-13. 